\title{
Bargaining with a residual claimant: An experimental study
}

Citation for published version (APA):

Embrey, M. S., Hyndman, K., \& Riedl, A. M. (2014). Bargaining with a residual claimant: An experimental study. Maastricht University, Graduate School of Business and Economics. GSBE Research Memoranda No. 039 https://doi.org/10.26481/umagsb.2014039

Document status and date:

Published: 01/01/2014

DOI:

10.26481/umagsb.2014039

Document Version:

Publisher's PDF, also known as Version of record

\section{Please check the document version of this publication:}

- A submitted manuscript is the version of the article upon submission and before peer-review. There can be important differences between the submitted version and the official published version of record.

People interested in the research are advised to contact the author for the final version of the publication, or visit the DOI to the publisher's website.

- The final author version and the galley proof are versions of the publication after peer review.

- The final published version features the final layout of the paper including the volume, issue and page numbers.

Link to publication

\footnotetext{
General rights rights.

- You may freely distribute the URL identifying the publication in the public portal. please follow below link for the End User Agreement:

www.umlib.nl/taverne-license

Take down policy

If you believe that this document breaches copyright please contact us at:

repository@maastrichtuniversity.nl

providing details and we will investigate your claim.
}

Copyright and moral rights for the publications made accessible in the public portal are retained by the authors and/or other copyright owners and it is a condition of accessing publications that users recognise and abide by the legal requirements associated with these

- Users may download and print one copy of any publication from the public portal for the purpose of private study or research.

- You may not further distribute the material or use it for any profit-making activity or commercial gain

If the publication is distributed under the terms of Article $25 \mathrm{fa}$ of the Dutch Copyright Act, indicated by the "Taverne" license above, 


\section{Maastricht University}

Matthew Embrey, Kyle Hyndman, Arno Riedl

Bargaining with a Residual Claimant: An Experimental Study

RM/14/039

\section{GSBE}

Maastricht University School of Business and Economics

Graduate School of Business and Economics

P.O Box 616

NL-6200 MD Maastricht

The Netherlands 


\title{
Bargaining with a Residual Claimant: An Experimental Study*
}

\author{
Matthew Embrey, ${ }^{\dagger}$ Kyle Hyndman ${ }^{\ddagger}$ and Arno Riedl ${ }^{\S}$
}

November 11, 2014

\begin{abstract}
We experimentally investigate a bargaining environment in which players negotiate over a fixed payment to one player, while the other player receives the residual from a random pie realization after subtracting the fixed payment. Contrary to the intuition that risk exposure is detrimental, we show that residual claimants are able to extract a risk premium, which is increasing in risk exposure. In some cases the premium is so high that it is advantageous to bargain over a risky pie rather than a risk-less pie. Contrary to theory, the comparatively less risk averse residual claimants benefit the most. Moreover, bargaining frictions increase as risk increases, and we document more frequent disagreements as risk increases. When given the chance to choose a less or more risky distribution over which to bargain, residual claimants tend to choose the more risky distribution only when there is the possibility of an equal-split ex-post. Our results suggest that theoretical bargaining models require some separation between the determinants of bargaining power and fair compensation for risk exposure.
\end{abstract}

JEL classification codes: C71, C92, D81

Keywords: Bargaining, Ex-post Risk, Reference Points

\section{Introduction}

In many bargaining situations where two parties must negotiate over the division of some surplus, one of them is exposed to a risk that is only resolved after an agreement has been reached. Examples of such ex-post risk abound. In the supply-chain management literature, two common forms of wholesale price contracts between a supplier and a retailer differ on

${ }^{*}$ We thank Gary Bolton, Natalia Candelo Londono, Guillaume Fréchette, Ben Greiner, Yusufcan Masatlioglu, Francesc Ortega, Anja Sautmann, Andrew Schotter, Rami Zwick as well as seminar participants at Queens College (CUNY), New York University and Indian School of Business (Hyderabad), and conference participants at the Design and Bargaining Workshop (Dallas, TX), Econometric Society European Meeting (Toulouse), Economic Science Association (Zurich, Fort Lauderdale), INFORMS (Minneapolis) and the NYU-Economics Alumni Conference (2013) for valuable comments. We gratefully acknowledge Maastricht University for financial support.

${ }^{\dagger}$ Embrey: Department of Economics, Maastricht University, PO Box 616, 6200 MD Maastricht, The Netherlands (E-mail: m.embrey@maastrichtuniversity.nl).

${ }^{\ddagger}$ Hyndman (Corresponding Author): Naveen Jindal School of Management, University of Texas at Dallas, 800 W. Campbell Rd (SM31), Richardson, TX 75080 (E-mail: KyleB.Hyndman@utdallas.edu).

${ }^{\S}$ Riedl: Department of Economics, Maastricht University, PO Box 616, 6200 MD Maastricht, The Netherlands (E-mail: a.riedl@maastrichtuniversity.nl). 
which of the parties bears the ex-post risk of unsold inventory (Cachon, 2004). In procurement projects, asymmetric exposure to risk arises when two parties transact but only one is liable for any cost overruns or for any damages from an accident (Lam et al., 2007). In labor-firm negotiations, employees generally receive a fixed salary, while the firm faces ex-post risk due to uncertainty over factors such as future demand or costs (Riedl and van Winden, 2012).

Indeed, asymmetric exposure to risk appears to have played a prominent role in two recent high-profile labor negotiations between sports leagues and their players unions: In the National Football League, "ownership wants the players to 'buy in' to the fact that running an NFL team requires an enormous allocation of risk not currently shared by the players to an appropriate level ... at one bargaining session, NFLPA representatives responded to the 'shared risk' argument with an offer to also share in profits ... that argument stopped the discussion in its tracks", and in the National Hockey League, "owners bear all of the risk. Players talk about desiring a partnership, but they certainly don't want to share the risk." 1 These quotes illustrate two things. First, asymmetric exposure to risk is a salient feature in real-world bargaining. Second, while important, it is not clear what role asymmetric risk exposure plays: the NFL example seems to suggest that exposure to risk may have been advantageous to owners, while the NHL example suggests that exposure to risk is something that both sides would like to minimize.

We provide empirical support for the former suggestion. Using laboratory experiments we show that residual claimants can benefit from their exposure to risk when bargaining. This contradicts the intuition that a mean-preserving spread should be detrimental to a risk-averse agent but is consistent with recent theoretical models of bargaining with risk (White, 2006, 2008). Furthermore, in contrast to the theory, we find that it is the less risk averse residual claimants who are better able to take advantage of this risk-exposure effect. However, the strategic advantage does not come for free. Bargaining over a risky surplus is associated with a greater chance of disagreement, compared to a risk-free surplus. We argue and provide evidence that this increase in bargaining friction is consistent with the idea that ex-post risk results in competing norms for what constitutes a fair allocation.

Despite the documented importance of asymmetric risk exposure in bargaining, it has received relatively little attention in the literature. ${ }^{2}$ Only relatively recently has the problem of

\footnotetext{
${ }^{1}$ The NFL quote comes from, "Key To The NFL CBA: Mitigating Risk", by Andrew Brandt, Forbes, March 7, 2011. The NHL quote comes from, "Allen: How to solve NHL labor dispute" by Kevin Allen, USA Today, September 15, 2012.

${ }^{2}$ Several papers look at bargaining with one-sided private information, where one player knows the size of the pie, while the other does not (though she may know the distribution). Examples include, Forsythe et al. (1991), Rapoport and Sundali (1996), Rapoport et al. (1996), Mitzkewitz and Nagel (1993) and Croson (1996). Forsythe et al. (1991) looks at both unstructured bargaining and a random dictator game to explain the incidence of strikes. Rapoport and Sundali (1996) looks at ultimatum offers, while Rapoport et al. (1996) considers a Nash demand game between the informed and uninformed players. These papers differ from ours in that the uncertainty in their environments results in asymmetric information between the players; this is not the case here. Perhaps the closest to the environment considered here is Deck and Farmer (2007)
} 
asymmetric exposure to risk been analyzed theoretically by White (2008). She provides mild conditions under which the agent exposed to risk (henceforth, the residual claimant) benefits from this risk exposure. Surprisingly, she also finds that a risk-averse residual claimant may actually prefer to bargain over a risky pie. Intuitively, when the residual claimant has decreasing absolute risk aversion the expected marginal utility of future earnings increases, effectively making her more patient and more willing to hold out for a better agreement. This strategic effect can outweigh the loss in expected utility from bearing additional risk. ${ }^{3}$

This striking theoretical result immediately suggests a number of empirical questions that we seek to investigate in this paper. First, in actual bargaining situations, is the residual claimant able to extract a risk premium for her exposure to risk? Our initial expectation was that this would be true, although possibly complemented by another, more behavioural, mechanism. In particular, the asymmetric exposure to risk could create competing norms for what constitutes a fair allocation. The fixed-payoff players would view the 50-50 split of the expected pie as fair, while residual claimants would view an allocation which compensates them for their risk as fair. Several studies (such as Gächter and Riedl, 2005; Bolton and Karagözoğlu, 2013; Karagözoğlu and Riedl, 2014) have shown that when there are competing norms for fairness, agreements often fall between these norms, which in the current setting would also result in a risk premium for the residual claimant.

Second, if residual claimants do extract a risk premium, is it sufficiently large to make them better off when being exposed to risk? This is a much more difficult hurdle to cross and, to the extent that fixed-payoff players can pull the agreement closer to their (self-serving) belief that a 50-50 division is fair, the behavioral mechanism outlined above works against the theoretical prediction. The third question inspired by theory is whether a residual claimant, if given the choice between distributions, would choose into the one with more ex-post risk? That is, do they judge for themselves that they are likely to be better off being exposed to risk?

A final issue, not adequately addressed by the baseline theoretical model, is the possibility of disagreement. Although, in general, little disagreement is observed in bargaining experiments without risk, bargaining in the field appears to often end in (at least temporary) disagreement. Recent literature suggests that under risk there may be a conflict between

who investigate a Nash demand game between two risk neutral parties, with one a residual claimant. They consider behavior under different arbitration rules and find that final-offer arbitration favors the residual claimant; however, the presence of arbitration increases conflict, relative to the no arbitration benchmark.

${ }^{3}$ The intuition for these results comes from the precautionary savings literature, where increasing the expected marginal utility of future consumption leading to a precautionary saving motive (Kimball, 1990). For the case of small additive risks, if $U^{\prime \prime \prime} \geq 0$, the residual claimant's receipts will rise with exposure to risk. Decreasing absolute risk aversion is a necessary and sufficient condition for the residual claimant to do better in expected utility terms, provided that the fixed-payoff player has pure fixed costs of bargaining. These results are derived in a Rubinstein bargaining setting. In an earlier working paper, White (2006) reports the results for the Nash bargaining solution, which we use as the theoretical benchmark for our unstructured bargaining experiments, and discuss in more detail in Section 2.1. 
ex-ante and ex-post fair outcomes (Fudenberg and Levine, 2012; Brock et al., 2013), which may generate disagreements even if agents would agree in situations without risk. Moreover, the possibility of self-serving biases and conflicting fairness ideals in case of risk, as discussed above, may also lead to disagreement. These considerations suggest that disagreement should be positively related to the riskiness the residual claimant is exposed to.

We address these questions through two experimental studies. In the baseline study, the distribution of the surplus being bargained over is exogenously determined. Subjects are assigned either the role of the residual claimant or the fixed-payoff player. They negotiate over a payment to the latter, with the residual claimant receiving the difference between the realized pie and the agreed payment. Subjects negotiate in this way ten times experiencing five distributions for the pie, which are ranked according to second-order stochastic dominance.

In answer to our first question, we find that residual claimants are able to extract a risk premium. On average, fixed-payoff players receive less than half of the expected pie and their payment is decreasing in the riskiness of the distribution. Consistent with a large body of bargaining literature (see Murnighan et al., 1987, and the references cited therein), the payment to the fixed-payoff player is decreasing in own risk aversion and increasing in the risk aversion of the residual claimant. In addition, consistent with our expectations, but in contrast to theory, asymmetric exposure to risk increases the frequency of disagreements. The disagreement rate is nearly $20 \%$ with the riskiest distribution and only $4 \%$ with the risk-free distribution. Regarding our second question, with an exogenous distribution, we find that some residual claimants do better in expected utility terms through their exposure to risk. However, in contrast to the theory, it is the comparatively less risk averse residual claimants that benefit the most.

To address our third question about whether residual claimants would choose to bargain over a riskier distribution, we use an endogenous distribution implementation: After experiencing each distribution - exogenously imposed - once, the residual claimant must choose between two distributions before bargaining begins. Since choosing the riskier distribution might be perceived as an unfair act (see, e.g., Konow, 1996, 2000, 2001; Cappelen et al., 2007; Cettolin and Tausch, 2013; Akbaş et al., 2014), and thus alter subsequent bargaining behavior, we considered two variations. In the first, the choice of the residual claimant is implemented for sure (transparent choice); in the second, the choice is implemented with probability 0.7 (non-transparent choice). The latter treatment masks intentionality by reducing the responsibility of the residual claimant when they bargain over the riskier distribution, which should increase the frequency with which residual claimants choose the riskier distribution (Dana et al., 2007). ${ }^{4}$

\footnotetext{
${ }^{4}$ Indeed, responses from our post-experiment survey from the exogenous sessions support the expectation that fixed-payoff players would be unwilling to compensate residual claimants for exposing the pair to greater risk. Three quotations expressing this view are: (1) "I would not accept less since I know [the residual claimant] took on more risks knowingly." (2) "I would kind of punish him for thanking [sic] this extra risk."
} 
Consistent with the results with exogenously specified distributions, we find that the relatively less risk averse residual claimants are more likely to choose into more risk. However, our results also indicate a general unwillingness to choose the riskier distribution, regardless of whether the choice is transparent or not. It is only when one alternative is riskless and the other has the possibility of an ex-post equal split that we observe frequent choice of the riskier distribution. We also observe that bargaining over the riskier distribution is associated with a 5-8 percentage point increase in the frequency of disagreements.

In summary, many of our empirical results are consistent with the benchmark theory, and are well-organised by the measures of risk that we collect. However, in contrast to this theory, we find that it is the relatively less risk averse residual claimants that benefit the most from ex-post risk. There are two possible mutually non-exclusive explanations for this unexpected result. First, since risk preferences are private information, fixed-payoff players may agree to compensate an "average" residual claimant for her exposure to risk. Then, when a fixedpayoff player is matched with a comparatively less risk averse residual claimant, the residual claimant is actually over-compensated for her risk. Second, our analysis of the bargaining process suggests that, when the pie is risky, fixed-payoff players - especially those who are relatively more risk averse - adopt a weaker bargaining position. Specifically, they demand less, they make larger concessions and they are more likely to accept than their residual claimant counterparts. As a result, these players earn a lower payoff to the advantage of (less risk averse) residual claimants.

The rest of the paper is organized as follows: Section 2 covers the design, predictions and results of the exogenous treatment, while Section 3 covers the endogenous treatments. In Section 4, we pool the data from all treatments and discuss important aspects of the bargaining process, with particular emphasis on trying to explain the observed deviations from the theoretical predictions. A final section concludes.

\section{Exogenous Distribution}

We implemented in the laboratory an unstructured bargaining environment in which pairs of subjects have four minutes to exchange offers and reach an agreement. Agents have to bargain over a pie, while knowing only the distribution of pie sizes. The actual size is determined after an agreement has been made. One agent is the residual claimant ( $\mathrm{RC})$; the other the fixed-payment player (FP). To divide the surplus, the agents must agree on the value of a fixed payment to the FP player that is paid irrespective of the realised value of the pie. The residual claimant receives what is left after this fixed payment is subtracted from the realised pie. If the agents do not agree then both receive zero.

We chose an unstructured bargaining framework because it provides a natural bargaining

(3) "If he had chosen over the certain outcome, I would pay a lower risk premium." 
environment in which players are able to express their views about what constitutes a fair division. Such an environment also avoids possible confounds that might arise due to an exogenous bargaining protocol. ${ }^{5}$

To investigate the effect of differences in ex-post risk on bargaining, five different pie distributions were implemented using a within-subject design. As a benchmark, the first distribution had no risk and subjects bargained over a pie size of $€ 20$ for sure. Four meanpreserving spreads were then used, varying the extremes of the possible outcomes (low risk versus high risk) and the number of possible outcomes (binary lottery versus tertiary lottery), where each outcome was equally likely. This within-subject variation was chosen to obtain a direct comparison of how well the same residual claimant does under differing risk conditions. Figure 1 gives the support of the four risky pie-distributions that were implemented.

Figure 1: Summary of the distributions with uncertainty.

\begin{tabular}{c|c|c|}
\multicolumn{1}{c}{ Tertiary } & Binary \\
\cline { 2 - 3 } Low risk & $(16,20,24)$ & $(16,24)$ \\
\cline { 2 - 3 } High risk & $(12,20,28)$ & $(12,28)$ \\
\hline
\end{tabular}

Fixing the number of possible outcomes, the distribution including the outcomes 12 and 28 is riskier than the one including 16 and 24. Fixing the extremes of the distribution, the binary distribution is riskier than the tertiary distribution. Finally, it is easy to see that the $(16,24)$ distribution second order stochastically dominates the $(12,20,28)$ distribution. Thus, the tertiary-high-risk condition is riskier than the binary-low-risk condition. From a behavioural perspective, a further difference between the binary and tertiary distributions is that the latter includes the 20 outcome. As a result, with the tertiary distributions, it is possible for both agents to earn ex-post the same payoff, should they agree to a 50-50 split of the expected value of the pie. With the binary distribution, the 50-50 split of the expected value of the pie necessarily leads to an ex-post unequal outcome.

\subsection{Theoretical Background and Hypotheses}

Since we implement an unstructured bargaining framework, the Nash bargaining solution of the cooperative game is used to provide the theoretical benchmark. In what follows, we outline the main theoretical predictions for the bargaining problem with asymmetric exposure

\footnotetext{
${ }^{5}$ In the alternative of alternating offers bargaining first-mover advantages and/or the probability of being proposer, as well as the chosen discount factor, may interact with the effect of risk exposure. These are extra complications we wanted to avoid. Moreover, in sequential bargaining often disadvantageous counter-offers are observed, which could compromise the analysis and interpretation of results regarding our research questions.
} 
to risk. A detailed account can be found in White (2006), which is the earlier working paper version of White (2008) and contains the results concerning the Nash bargaining solution.

In our setting, the Nash bargaining solution is found by maximising the product of the expected utilities of the FP and RC players. That is, given the amount to divide is a random variable, $\pi$, with support $\left[\pi_{\min }, \pi_{\max }\right]$, the solution is a payment to the FP player, $y$, that maximises

$$
U_{F P}(y) \cdot \mathbb{E}_{\pi}\left[U_{R C}(\pi-y)\right] .
$$

For a fixed distribution of $\pi$, since disagreement represents the worst outcome, the solution will have the usual comparative statics with respect to the utility functions of the FP and RC players: for either player, greater concavity in their utility function will result in a lower share of the bargaining surplus (see, for example, Roth and Rothblum, 1982).

Fixing the preferences of the players, Proposition 6 of White (2006) shows that a residual claimant's share of the pie will increase with the addition of a small additive risk, compared to the no risk case, as long as:

$$
-\frac{u^{\prime \prime \prime}}{u^{\prime \prime}}>-\frac{u^{\prime}}{u}
$$

If we assume that players have constant relative risk aversion (CRRA), $u_{i}(x)=\frac{1}{1-\rho_{i}} x^{1-\rho_{i}}$ for $i \in\{R C, F P\}$, then the RC's expected receipts will always increase with exposure to risk. ${ }^{6}$ In the experiment subjects bargain over an amount to allocate to the FP player. This result says that FP player's payoff should decrease when the distribution of the pie gets riskier.

However, a decreasing payment to the FP player does not always imply increasing welfare for the RC player. A necessary and sufficient condition for her welfare to improve with a small additive risk, compared to the no risk case, is (White, 2006, Proposition 7):

$$
u_{R C}^{\prime \prime}(\bar{\pi}-y) / u_{R C}^{\prime}(\bar{\pi}-y)-u_{R C}^{\prime \prime \prime}(\bar{\pi}-y) / u_{R C}^{\prime \prime}(\bar{\pi}-y) \geq u_{F P}^{\prime}(y) / u_{F P}(y)-u_{F P}^{\prime \prime}(y) / u_{F P}^{\prime}(y) .
$$

Assuming CRRA utility, this condition reduces to $y \geq \frac{\bar{\pi}}{2}$. That is, the residual claimant will do better in expected utility terms if she would, in the risk-free setting, receive less than half of the pie. Since this happens whenever $\rho_{R C}>\rho_{F P}$, her welfare should increase with the addition of a small additive risk whenever she is more risk averse than the FP player.

In our experiment, the risks that the $\mathrm{RC}$ is exposed to are not small, meaning this condition will not be exact. Indeed, our numerical calculations show that $\rho_{R C}>\rho_{F P}$ is neither necessary nor sufficient for the RC's welfare to improve when exposed to the risks in our experiment. In particular, as long as both players are not too risk averse, then for some distributions, the RC may do better even if she is slightly less risk averse than the FP player. On the other hand, as risk aversion increases, an RC who is slightly more risk averse than the

\footnotetext{
${ }^{6}$ The CRRA family of utility functions is used rather than, for example, CARA because the theoretical predictions require decreasing absolute risk aversion. Indeed, with CARA utility, the results would not hold. As we will demonstrate, the theoretical predictions based on CRRA preferences provide a suitable benchmark with which to interpret our results.
} 
FP player may not have a welfare improvement relative to the risk-free distribution. Despite these caveats, $\rho_{R C}>\rho_{F P}$ is a useful approximation for the $\mathrm{RC}$ to do better in expected utility terms from being exposed to risk. This can be seen from Figure 2, which plots the region (shaded in grey) over which RCs are predicted to do better in expected utility terms for two distributions used in the experiment: $(16,20,24)$, which is the least risky of the uncertain distributions, and $(12,28)$, which is the the most risky. The broken 45 degree line indicates the locus for which the RC and FP players have identical risk preferences $\left(\rho_{R C}=\rho_{F P}\right)$.

Figure 2: Region Over Which Exposure to Risk is Advantageous (Shaded in Gray)

(a) $(16,20,24)$

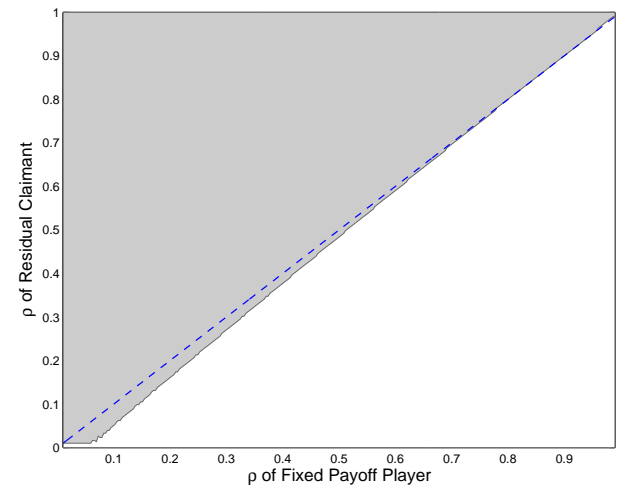

(b) $(12,28)$

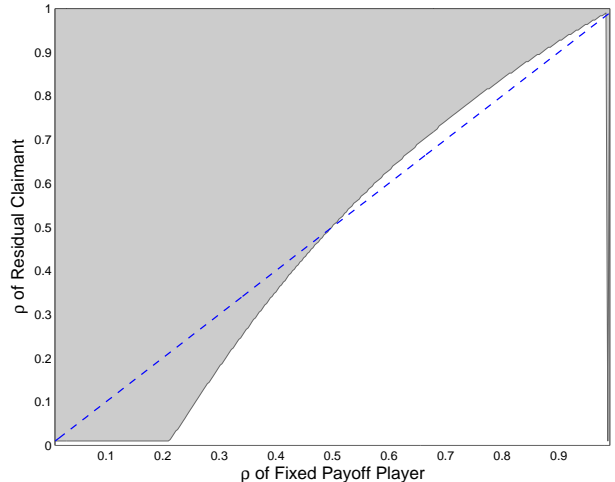

From the above analysis, we have the following predictions that we will test in our subsequent data analysis.

Hypothesis 1 As the riskiness of the bargaining distributions increases, the amount allocated to the fixed-payoff player declines.

HyPOTHESIS 2 The amount allocated to the fixed-payoff player is decreasing in $\rho_{F P}$ and increasing in $\rho_{R C}$, regardless of the riskiness of the distribution, provided that $\rho_{R C}>0$.

HYPothesis 3 To a first approximation, whenever $\rho_{R C}>\rho_{F P}$, the residual claimant's welfare will be higher when faced with a risky distribution than a riskless distribution.

Hypothesis 4 Across all distributions, the frequency of agreements is $100 \%$.

Hypotheses 2 and 3 concern two distinct comparative statics that could be confused. Hypothesis 2 fixes the distribution over which players bargain and varies risk preferences, while Hypothesis 3 fixes the risk preferences of the players and varies the distribution. Figure 3(a) shows how the payment to the FP player, with risk parameter fixed at $\rho_{F P}=\frac{1}{2}$, varies as the risk parameter of the RC player varies. Consistent with Hypothesis 2, as the RC 
Figure 3: Example of Payment to FP Player and Certainty Equivalent for RC Player

(a) Payment to FP Player

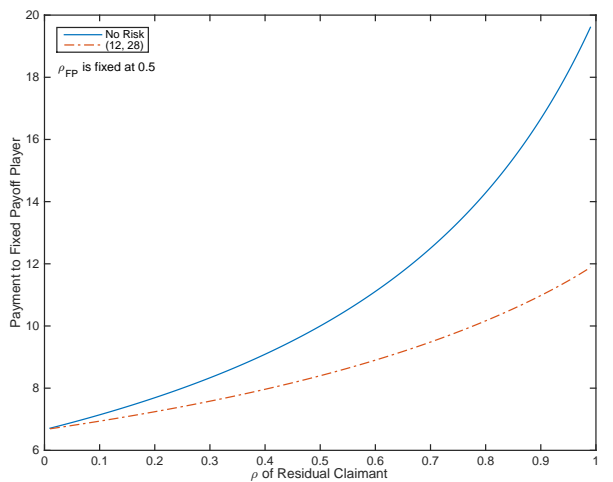

(b) Certainty Equivalent for RC Player

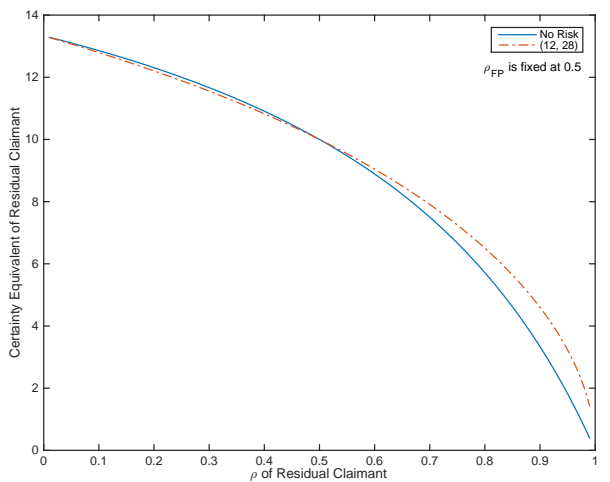

player's risk aversion increases, the payment to the FP player increases; however, the absolute compensation for risk is greater when the pie is risky (i.e., the curve is much flatter).

Figure 3(b) plots the certainty equivalent of the $\mathrm{RC}$ player as a function of her risk parameter. Again, consistent with Hypothesis 2, the certainty equivalent is decreasing as risk aversion increases. To see Hypothesis 3, one should compare the solid and dashed lines that correspond to the $(20)$ and $(12,28)$ distributions, respectively. As can be seen, approximately when $\rho_{R C}>\frac{1}{2}=\rho_{F P}$, the welfare of the RC player becomes larger when bargaining over the risky distribution. Importantly, however, this does not mean that, in a world in which risk preferences are private information, the residual claimant would try to pretend to be more risk averse. As Figure 3 clearly demonstrates, for a fixed distribution, increased risk aversion is disadvantageous.

\subsection{Experimental Procedures}

For the exogenous pie distribution experiments, 48 subjects ( 25 female, 23 male) participated in two sessions with 24 subjects each. Each session was split into two matching groups of 12 , to give 4 matching groups in total. The experiments took place at the BEElab of Maastricht University, and all participants were students at Maastricht University recruited using ORSEE (Greiner, 2004). Sessions took less than 1 hour and 30 minutes, and on average subjects earned between $€ 20$ and $€ 23$.

Each session consisted of two parts. At the beginning of the first part, subjects were randomly assigned either the role of the RC or the FP player, and kept the same role throughout the experiment. At the beginning of a bargaining round, subjects were randomly matched into pairs (one RC and one FP) and received information about the distribution of possible pie sizes over which they would bargain. During the round, subjects had four minutes 
to reach an agreement, which was framed as a payment to the FP player. ${ }^{7}$ Subjects were free to make as many offers as they wished during this time, and subsequent offers were not required to improve upon one's previous offer. An agreement was reached when one of the two accepted the current offer of the other player. No communication beyond sending and accepting offers was permitted.

Subjects were randomly assigned into one of two matching groups, which were run in parallel on separate z-Tree servers (Fischbacher, 2007), and randomly rematched between bargaining rounds within their matching group. ${ }^{8}$ During a session, the order of distributions was the same for all subjects in a matching group. Across matching groups the order of presentation was varied, except that in rounds 1 and 10 subjects always bargained over the risk-free pie of $€ 20$. Within a matching group, the order of presentation of the four uncertain pies was the same in bargaining rounds 2 to 5 and bargaining rounds 6 to 9 . Thus, by bargaining round 6 , every subject in every session had experienced each pie distribution exactly once. Four order combinations were used by systematically varying whether the binary lotteries or the tertiary lotteries were shown first, and whether the low risk or high risk came first. ${ }^{9}$ After the 10 bargaining rounds were completed, one round was randomly selected to determine their payoff from this part of the experiment.

During the second part of the experiment, subjects were given a risk elicitation task. Specifically, the certainty equivalent for six different binary lotteries was elicited using an implementation similar to Cettolin and Tausch (2013) (see also Bruhin et al., 2010). ${ }^{10}$ This risk elicitation stage was included in all sessions of both our exogenous and endogenous distribution experiments. For each subject, the elicited certainty equivalents were used to estimate the $\rho$ parameter assuming a CRRA functional form. The vast majority of residual

\footnotetext{
${ }^{7}$ See Section B.1 of the Supplementary Materials for sample instructions. Proposals were restricted to ensure that the residual claimant would never go bankrupt. That is, the most that the fixed-payoff player could claim or be offered was the lowest possible realisation of the pie (i.e., 12, 16 or 20 depending on the distribution). In all cases, this was greater than half of the expected pie size of 20.

${ }^{8}$ The re-matching scheme means that all observations within a matching group are potentially correlated. Consequently, statistical significance in the subsequent results sections is established using a regression-based approach that uses cluster-robust standard errors, allowing for arbitrary correlation between observations within a matching group. That is, the statistical approach does not assume that observations within a matching group are independent; only that those across matching groups are independent. Where possible, non-parametric tests on matching-group averages were run as a robustness check, without any notable affect on the conclusions, and are available upon request. For a recent exposition on "session-effects" in experimental data analysis, see Fréchette (2012).

${ }^{9}$ That is, the four orders were: $(16,24),(12,28),(16,20,24)$ and $(12,20,28) ;(12,28),(16,24),(12,20,28)$ and $(16,20,24) ;(16,20,24),(12,20,28),(16,24)$ and $(12,28) ;(12,20,28),(16,20,24),(12,28)$ and $(16,24)$.

${ }^{10}$ The six lotteries were: $(15,1 / 2 ; 0,1 / 2),(14,1 / 2 ; 6,1 / 2),(20,2 / 5 ; 0,3 / 5),(18,1 / 2 ; 2,1 / 2),(10,3 / 4 ; 0,1 / 4)$ and $(12,2 / 3 ; 0,1 / 3)$. Lotteries $(14,1 / 2 ; 6,1 / 2)$ and $(18,1 / 2 ; 2,1 / 2)$ were chosen to provide some gambles similar to those the RC faced in the bargaining task; these are simply the $(16,24)$ and $(12,28)$ pie distributions minus an FP payment of 10. The other four lotteries were chosen to aid the estimation of CRRA coefficients. Instructions were given via the computer interface after the bargaining task had been completed. One decision was chosen at random and paid. See the supplementary materials for the implemented zTree interface. In addition to the payoff from bargaining and the risk elicitation, subjects also received a $€ 2$ show-up fee.
} 
claimants are estimated to be risk averse (see Figure A.1 of Appendix A).

An estimate of subjects' risk preferences is important for a number of reasons. First, the conditions provided in White (2006) for the Nash bargaining solution, as well as the standard results on outcomes without ex-post risk, are based on the risk attitudes of the bargaining parties. With these estimates, the predictions can be tested at the match level and, thus, more precisely. Furthermore, a measure of risk preferences is required to address any hypothesis concerning the welfare of residual claimants.

At the end of the experiment, subjects answered a series of survey questions, including for each of the five pie distributions, their judgement of a fair allocation to the FP player. Specifically, they were asked, "what would be, in your opinion, a "fair' amount to give to the [fixed-payment player] from the vantage point of a non-involved neutral arbitrator." (Babcock et al., 1995; Gächter and Riedl, 2005)

\section{$2.3 \quad$ Results}

We begin our analysis by presenting some basic summary statistics of the experimental results. Table 1 presents a summary of the bargaining outcomes. As can be seen, the FP players earn on average less than half of the expected pie for each distribution (ordered from risk-free to riskiest in the table). This average, however, includes the disagreement payment of zero when the players fail to reach an agreement. Focussing on agreements, which is the primary concern of the benchmark theory, the average agreed FP payment is decreasing in the riskiness of the distribution, consistent with Hypothesis $1 .^{11}$

The presence of risk also increases bargaining frictions. There are more disagreements with risk than without risk, statistically rejecting Hypothesis 4 in the case of the riskiest distribution, $(12,28) .{ }^{12}$ Moreover, with risk if an agreement is reached, more time is required to reach it. Along with the greater bargaining friction, fairness assessments diverge as the riskiness of the distribution increases. FP players generally view the 50-50 division as fair, while many residual claimants report a fair allocation that compensates them for their risk. ${ }^{13}$ Moreover, for all distributions with risk, average agreed payments are between the (selfserving) fairness perceptions of the $\mathrm{RC}$ and the $\mathrm{FP}$ players.

Table 2 investigates Hypotheses 1 and 2 directly. Since the predictions of the benchmark theory primarily concern the nature of agreements, the dependent variable in these random-

\footnotetext{
${ }^{11}$ See the top two panels of Table A.1 in Appendix A for the result of a complete pairwise comparison.

${ }^{12}$ See the disagreements panel of Table A.1 in Appendix A for the result of a complete pairwise comparison.

${ }^{13}$ Overall, the fairness assessments of the RC players are significantly below those of the FP players when there is risk. This result is primarily driven by the two high-risk distributions. The null hypothesis that the assessments are the same is tested using a regression-based approach with standard errors clustered at the matching-group level. Starting with the deterministic pie and going in order of increasing riskiness, the pvalues are $0.721,0.081,0.206,0.004$ and 0.003 , respectively. It is also not possible to reject the null hypothesis the fairness assessments of FP players is equal to the 50-50 split for all distributions. For the RC players, this can be rejected for all distributions with risk.
} 
Table 1: Bargaining Outcomes and Fairness Perceptions in the Exogenous Environment

\begin{tabular}{|c|c|c|c|c|c|c|}
\hline \multirow{2}{*}{$\begin{array}{l}\text { Distribution } \\
\text { of Pie }\end{array}$} & \multirow{2}{*}{$\begin{array}{c}\text { Final FP } \\
\text { Earnings }(€)\end{array}$} & \multirow{2}{*}{$\begin{array}{c}\text { Agreed FP } \\
\text { Payments }(€)\end{array}$} & \multirow{2}{*}{$\begin{array}{c}\text { Disagreements } \\
(\%)\end{array}$} & \multirow{2}{*}{$\begin{array}{l}\text { Remaining } \\
\text { Time (sec) }\end{array}$} & \multicolumn{2}{|c|}{ Fair Payment to FP } \\
\hline & & & & & $\mathrm{FP}(€)$ & $\mathrm{RC}(€)$ \\
\hline$(20)$ & 9.71 & 10.16 & 4.2 & 151 & 9.96 & 9.92 \\
\hline$(16,20,24)$ & 9.04 & 9.68 & 6.2 & 70 & 10.33 & 9.44 \\
\hline$(16,24)$ & 8.17 & 9.61 & 14.6 & 38 & 10.29 & 9.44 \\
\hline$(12,20,28)$ & 8.10 & 9.09 & 10.4 & 37 & 9.88 & 8.42 \\
\hline$(12,28)$ & 7.14 & 8.80 & 18.8 & 53 & 9.58 & 8.06 \\
\hline
\end{tabular}

effects regressions is the agreed payment to the FP player. The indicator variables $\mathbf{1}[(\cdot)]$ take value 1 for the indicated distribution and 0 otherwise. The first specification confirms that risk reduces the agreed payment for FP players, and significantly so for all but the least risky distribution. The second specification uses the variance of the distributions, normalized so that the variance of the riskiest distribution is one, as a single measure and shows that this also captures the effect of this treatment variation.

With this simplified specification for the treatment variation, the last two columns include estimates of the risk attitude of the $\mathrm{FP}\left(\rho_{F P}\right)$ and $\mathrm{RC}\left(\rho_{R C}\right)$ players as explanatory variables. These specifications test Hypothesis 2. Consistent with this hypothesis, the coefficient on $\rho_{F P}$ is significantly negative, while the coefficient on $\rho_{R C}$ is significantly positive. That is, fixing the distribution, being more risk averse worsens a subject's bargaining position irrespective of their role. Notably, the marginal effect of risk aversion appears smaller in magnitude for the RC player than the FP player. As specification 4 illustrates, this results from the interaction between $\rho_{R C}$ and risk. For fixed FP and RC preferences, increasing the risk of the pie improves the bargaining position of the latter, but the overall effect is still negative. For a fixed distribution, the $\rho$ coefficients for the FP and RC players have the opposite effect on agreed FP payments, with a comparable magnitude in the risk-free case. That is, the elicited risk preferences affect the agreed FP payment in the direction predicted by theory; recall Figure 3 for an illustration of this.

While the regressions reported in Table 2 show that agreed payments vary with risk preferences in the predicted manner, a stronger test of the theory would be to examine the relationship between the agreed payment predicted by the Nash bargaining solution, given the elicited risk preferences of the bargaining pair. Figure 4 plots the observed cumulative distribution of agreed and predicted payments. This figure provides a number of insights. First, when there is no risk, nearly all agreements are a 50-50 division of the pie. That is, differences in preferences lose salience and the norm to divide the pie equally dominates. Second, for the risky distributions, there is a close correspondence between the observed and predicted distributions of payoffs, in particular for the high risk distributions. Finally, agreed FP payments are less on average than would be predicted by the theory; indeed, for 
Table 2: Linear Random-Effects Regression of Agreed Payments to the FP Player

\begin{tabular}{|c|c|c|c|c|}
\hline \multirow[b]{3}{*}{$\mathbf{1}[(16,20,24)]$} & \multicolumn{4}{|c|}{ Agreed FP Payments } \\
\hline & (1) & \multirow[t]{2}{*}{$(2)$} & \multirow[t]{2}{*}{$(3)$} & $(4)$ \\
\hline & $-0.41 \quad(0.439)$ & & & \\
\hline $\mathbf{1}[(16,24)]$ & $-0.48^{* *}(0.202)$ & & & \\
\hline $\mathbf{1}[(12,20,28)]$ & $-1.11^{* *}(0.467)$ & & & \\
\hline $\mathbf{1}[(12,28)]$ & $-1.32^{* * *}(0.324)$ & & & \\
\hline Variance & & $-1.31^{* * *}(0.263)$ & $-1.32^{* * *}(0.275)$ & $-0.68^{* *} \quad(0.340)$ \\
\hline$\rho_{F P}$ & & & $-1.99^{* * *}(0.651)$ & $-1.95^{* * *}(0.667)$ \\
\hline$\rho_{R C}$ & & & $1.05^{* * *}(0.388)$ & $1.64^{* * *}(0.456)$ \\
\hline$\rho_{R C} \times$ Var & & & & $-1.48^{* * *}(0.443)$ \\
\hline Constant & $10.12^{* * *}(0.098)$ & $10.00^{* * *}(0.101)$ & $10.07^{* * *}(0.195)$ & $9.81^{* * *}(0.191)$ \\
\hline$\overline{\mathrm{R}^{2}}$ & 0.09 & 0.08 & 0.17 & 0.17 \\
\hline Observations & 195 & 195 & 195 & 195 \\
\hline
\end{tabular}

Notes: Data includes only observations for which $\left|\rho_{i}\right|<1$ for both RC and FP players. ${ }^{* * *} 1 \%,{ }^{* *} 5 \%,{ }^{*} 10 \%$ significance using standard errors clustered at the matching group level.

all distributions, the difference is significant $(p<0.01) .{ }^{14}$

We next turn to Hypothesis 3, which predicts that exposure to risk is advantageous to the RC player (in expected utility terms) approximately when she is more risk averse than the FP player. To measure the RC player's welfare, the estimated risk attitude is used to calculate the certainty equivalent of an agreement. The certainty equivalent gives a measure that is comparable across subjects since it measures welfare on a common scale, allowing observations to be pooled across subjects for the regression analysis. Since subjects are randomly re-matched between bargaining rounds, comparing the agreed payments in rounds with risk to those without risk misses the exact counter-factual of the hypothesis as a given $\mathrm{RC}$ player is likely to be bargaining with different FP players in each round.

The regressions reported in Table 3 address this missing counter-factual by including an indicator variable for whether the RC player is more risk averse than the $\mathrm{FP}$ player $\left(\mathbf{1}\left[\rho_{R C}>\rho_{F P}\right]\right)$, as well as an indicator variable for a risky distribution $(\mathbf{1}[$ Var. $>0])$ and an interaction term. If Hypothesis 3 is correct then the sum of the coefficients of $\mathbf{1}$ [Var. $>0$ ] and the interaction should be positive. The results of this regression can be seen in the first column. ${ }^{15}$ While the coefficient on risk is significantly positive, the coefficient on the

\footnotetext{
${ }^{14}$ Regression-based test of the difference between actual and predicted agreed FP payment on a constant, using standard errors clustered at the matching group level. The reported p-value is the significance of the (negative) constant term.

${ }^{15}$ It should be noted that the elicited risk parameter, $\rho_{R C}$, appears on both sides of the regression equation: it is used to calculate the certainty equivalent for the dependent variable and it is used to determine the value of the independent variables $\mathbf{1}\left[\rho_{R C}>\rho_{F P}\right]$ and $\mathbf{1}[$ Var. $>0] \times \mathbf{1}\left[\rho_{R C}>\rho_{F P}\right]$. Error in the measurement of $\rho_{R C}$ would result in correlation between the independent variables and the error term, resulting in biased coefficient estimates. Under the hypothesis of the benchmark theory, this bias can be signed. To see this, suppose that, due to measurement error, the $\rho$ estimate for an RC is over estimated. The over estimate would result in both under estimating the certainty equivalent of an agreement made under risk and over estimating whether the RC should benefit from bargaining under risk - since $\mathbf{1}\left[\rho_{R C}>\rho_{F P}\right]$ is more likely to be one.
} 
Figure 4: Observed Versus Predicted Agreed Payments to the FP Player

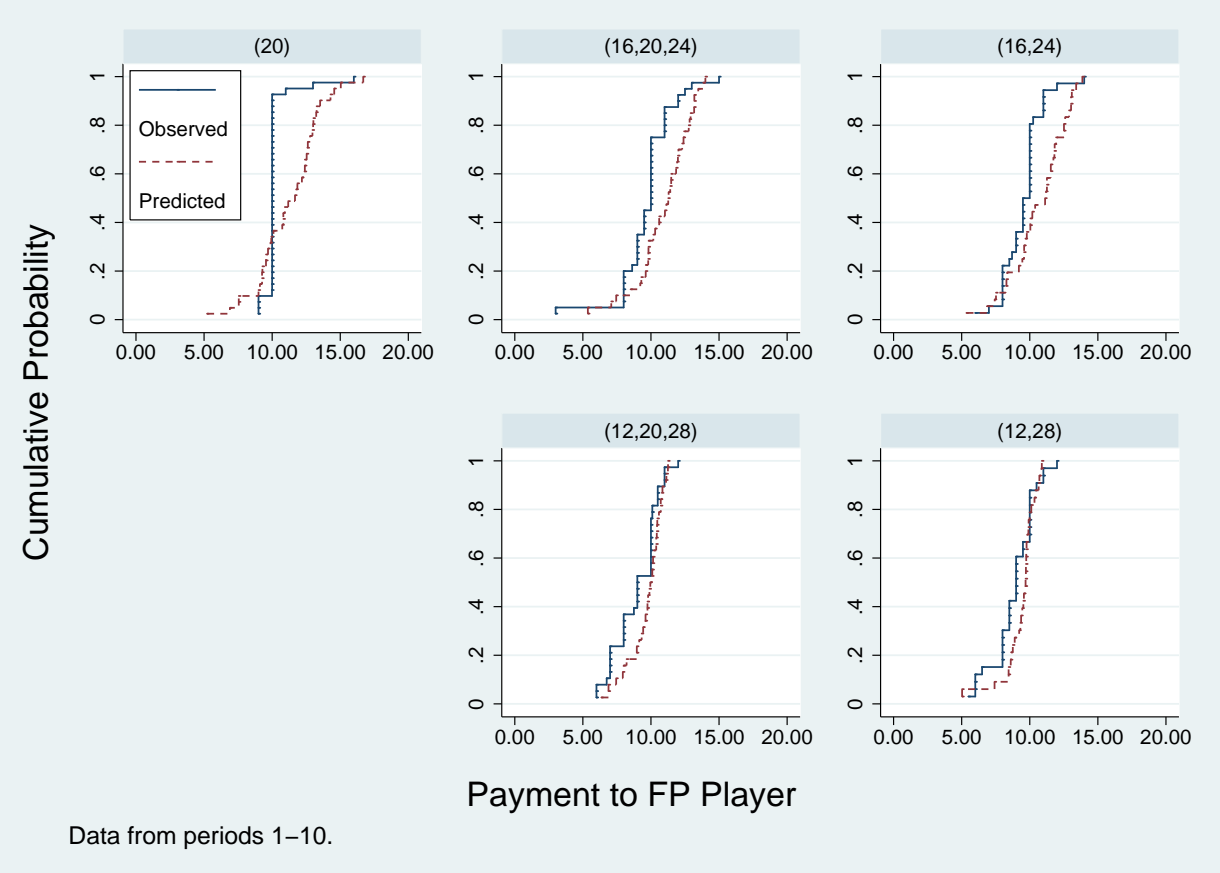

interaction term is negative and larger in magnitude than the coefficient on risk. Therefore, contrary to the theoretical prediction, it is actually the less risk averse residual claimants who gain in welfare terms when bargaining over a risky distribution. To illustrate this further, the second and third columns of Table 3 estimate the aggregate effect of bargaining over risk, versus no risk, for two subsamples of RC players. The second column, where $\rho_{R C} \leq 0.5$, represents the sample of less risk averse RC players; the third column, where $\rho_{R C}>0.5$, is the sample of more risk averse RC players. ${ }^{16}$ As can be seen, bargaining over risk significantly increases the estimated welfare of the less risk averse group, but does not have a significant impact on the more risk averse group.

To summarize the results thus far, there is strong support for Hypotheses 1 and 2: agreed payments to FP players are decreasing in riskiness and, for a given distribution, the payment is increasing in the risk aversion of the RC player and decreasing in the FP's own risk aversion. We do not find support for Hypothesis 3, that predicts it should be the more risk averse RCs who benefit from exposure to risk. While we identify RCs that seem to gain from the exposure to risk, it is rather the relatively less risk averse that benefit. Finally, Hypothesis

Thus, the estimated coefficients would be an under-estimate of the impact of variables $\mathbf{1}\left[\rho_{R C}>\rho_{F P}\right]$ and $\mathbf{1}[$ Var. $>0] \times \mathbf{1}\left[\rho_{R C}>\rho_{F P}\right]$.

${ }^{16}$ The exact cut-off is not important. Note that in the sample of RC players with $|\rho|<1$, none have an estimated $\rho$ below zero; the average $\rho$ estimate is 0.44 , and for every match with an RC player with a $\rho>0.5$, the RC player had a higher $\rho$ than the FP player they were matched with. 
Table 3: Linear Random-Effects Regression of the Certainty Equivalent of Agreements for RC Players

\begin{tabular}{|c|c|c|c|}
\hline \multirow{5}{*}{$\begin{array}{l}\mathbf{1}[\text { Var. }>0] \\
\mathbf{1}\left[\rho_{R C}>\rho_{F P}\right] \\
\mathbf{1}[\text { Var. }>0] \times \mathbf{1}\left[\rho_{R C}>\rho_{F P}\right] \\
\text { Constant }\end{array}$} & \multicolumn{3}{|c|}{$\begin{array}{l}\text { Certainty Equivalent of Agreement for RC Player } \\
\begin{array}{ll}(1) & (2)\end{array}\end{array}$} \\
\hline & $0.74^{* * *}(0.283)$ & $0.63^{* * *}(0.222)$ & $-0.60 \quad(0.556)$ \\
\hline & $-0.05 \quad(0.481)$ & & \\
\hline & $-0.87^{* * *}(0.177)$ & & \\
\hline & $9.92^{* * *}(0.268)$ & $10.08^{* * *}(0.102)$ & $9.61^{* * *}(0.409)$ \\
\hline $\mathrm{R}^{2}$ & 0.06 & 0.02 & 0.03 \\
\hline Observations & 195 & 111 & 84 \\
\hline RC sub-sample & - & $\rho_{R C} \leq 0.5$ & $\rho_{R C}>0.5$ \\
\hline
\end{tabular}

Notes: Data includes only observations for which $\left|\rho_{i}\right|<1$ for both $\mathrm{RC}$ and $\mathrm{FP}$ players. ${ }^{* * *} 1 \%,{ }^{* *} 5 \%,{ }^{*} 10 \%$ significance using standard errors clustered at the matching group level.

4 is rejected: as the risk increases, the frequency of disagreements increases and significantly so for the riskiest distribution.

\section{Endogenously Chosen Distribution}

The welfare result of White (2006) predicts that some RC players achieve a higher welfare when bargaining over more risky distributions. An immediate corollary to this result is that such an RC player should, if given the choice, choose to bargain over a riskier distribution. This observation suggests an alternative way of testing the welfare predictions by asking the $\mathrm{RC}$ player to choose between distributions. This approach avoids the need to calculate the certainty equivalent of observed agreements, since the observed choice reveals the RC player's preferred environment. Furthermore, giving the RC player a choice between distributions avoids the missing counterfactual from comparing behaviour across bargaining rounds.

While the welfare results from the exogenous-distribution experiment identified RCs that benefit from risk, they were contrary to our hypothesis in that the wrong group seemed to benefit - namely, the relatively less rather than more risk averse. To test the robustness of this result and to further understand the relation between $\mathrm{RC}$ players welfare and risk exposure, we conducted a set of endogenous-distribution treatments. Specifically, we ask under what conditions would the RC player choose the riskier distribution? The benchmark theory suggests that it should be the relatively more risk averse $\mathrm{RC}$ players, while our previous empirical results suggest it should be the relatively less risk averse.

There are, however, two notable factors that might make an RC player reluctant to choose a riskier distribution, even though she might otherwise expect a higher welfare. First, the previous welfare result was for agreed payments, yet disagreements were also more likely with riskier distributions. Factoring in the increased likelihood of disagreement, it is less clear that, even for the less risk averse RC players, it is better to bargain over a riskier distribution. It 
was also the case that the probability of disagreement depends on whether the distribution is binary or tertiary (see, for example, Table 1). Consequently, the endogenous-distribution design systematically varies within-subjects the alternative distributions available to the RC player. It exposes the RC players to a wide variety of comparisons: certainty versus a binary distribution, certainty versus a tertiary distribution, binary versus tertiary and high versus low risk, for both the binary and tertiary distributions.

Second, a large literature in behavioral economics emphasizes the role of bargaining norms, often based around fairness considerations and the role of intentions; that is, how "kindly" other players' actions are perceived to be. As a result, FP players may refuse to compensate the $\mathrm{RC}$ for the risk they are exposed to if they knew that the risky distribution was deliberately chosen. If so, the RC player may be concerned that the other player may not perceive her position as credible, resulting in her choosing the safer distribution. If this behavioral reasoning turns out to be important, then the literature on accountability and fairness suggests a role for how accountable the RC player is for the choice of distribution (Konow, 1996; Cettolin and Tausch, 2013). If there is some randomness about which pie the players bargain over, then the FP player cannot conclude with certainty that the riskier distribution was actually chosen by the RC, making him (perhaps) more willing to compensate her for the extra risk. If this is the case, this lack of transparency could restore the RC player's willingness to choose the riskier distribution.

These considerations led to a $2 \times 2$ design, summarised in Figure 5. The first dimension varies the riskiness of some of the distributions that the RC player must choose between. As there are many possible binary combinations between the five distributions, two sets were used. Each set has the same general structure: certainty versus binary, certainty versus tertiary, binary versus tertiary, low risk binary versus high risk binary and low risk tertiary versus high risk tertiary. In the low risk set, the low risk distributions are used in the first three choices; in the high risk set, the high risk distributions are used. Thus, across all treatments, we include eight out of the ten possible combinations, which allows us to keep the number of rounds at five and, thus, comparable to the exogenous-distribution experiment. ${ }^{17}$

The second dimension varies the frequency with which the RC's choice of distribution would be implemented. In the transparent choice setting, the RC's chosen distribution is always implemented, and the FP player is aware of this fact, as well as the choice faced by the RC. In the non-transparent choice setting, the RC's chosen distribution is implemented $70 \%$ of the time and the non-chosen distribution $30 \%$ of the time. The FP player knows the choice problem faced by the residual claimant, but not the actual choice made by the residual claimant. The contrast between the transparent and non-transparent treatments can be used to establish whether being accountable for the choice of bargaining distribution is a salient consideration for RC players. Despite our ex-ante expectations that it might have

\footnotetext{
${ }^{17}$ The only missing combinations are $(16,24)$ versus $(12,20,28)$ and $(16,20,24)$ versus $(12,28)$.
} 
Figure 5: Summary of the Treatment Variations for the Endogenous Environment

\begin{tabular}{|c|c|c|}
\hline & Transparent & Non-transparent \\
\hline Low risk & $\begin{array}{l}(20) \text { vs }(16,24) \\
(20) \text { vs }(16,20,24) \\
(16,24) \text { vs }(16,20,24) \\
(16,24) \text { vs }(12,28) \\
(16,20,24) \text { vs }(12,20,28) \\
\text { Probability choice implemented }=1\end{array}$ & $\begin{array}{l}(20) \text { vs }(16,24) \\
(20) \text { vs }(16,20,24) \\
(16,24) \text { vs }(16,20,24) \\
(16,24) \text { vs }(12,28) \\
(16,20,24) \text { vs }(12,20,28) \\
\text { Probability choice implemented }=0.7\end{array}$ \\
\hline High risk & $\begin{array}{l}(20) \text { vs }(12,28) \\
(20) \text { vs }(12,20,28) \\
(12,28) \text { vs }(12,20,28) \\
(16,24) \text { vs }(12,28) \\
(16,20,24) \text { vs }(12,20,28) \\
\text { Probability choice implemented }=1\end{array}$ & $\begin{array}{l}(20) \text { vs }(12,28) \\
(20) \text { vs }(12,20,28) \\
(12,28) \text { vs }(12,20,28) \\
(16,24) \text { vs }(12,28) \\
(16,20,24) \text { vs }(12,20,28) \\
\text { Probability choice implemented }=0.7\end{array}$ \\
\hline
\end{tabular}

a significant bearing on RC players distribution choice, transparency did not prove to be a salient issue. Since our primary question is whether, and if so which, RC players benefit from risk, the results from the transparent versus non-transparent contrast are relegated to the supplementary materials. The subsequent results section will pool data from transparent and non-transparent sessions. ${ }^{18}$

\subsection{Theoretical Predictions and Hypotheses}

Following the analysis from Section 2.1, the benchmark theory (White, 2006) predicts, to a first order approximation, that the RC player would choose the riskier distribution whenever they are more risk averse than the FP player. However, the random matching scheme and timing of the distribution choice means that the $\mathrm{RC}$ player does not know the risk attitude of the FP player when making the choice. Nonetheless, for a given pool of FP players, the more risk averse the $\mathrm{RC}$ player is the more likely she is to be more risk averse than her randomly selected counter-part. These considerations lead to the following theory-driven hypothesis:

HYPOTHESIS 5 The likelihood of choosing the risky distribution is increasing in the risk aversion of the RC player.

Note, however, that the results from the exogenous-distribution sessions, in which the relatively less risk averse RC players were the main beneficiaries of risk, would suggest the opposite prediction. Therefore, an alternative hypothesis is that the likelihood of choosing the risky distribution is decreasing in the risk aversion of the $\mathrm{RC}$ player.

\footnotetext{
${ }^{18}$ See Appendix $\mathrm{C}$ for details of the transparent versus non-transparent contrast.
} 


\subsection{Experimental procedures}

In this experiment only subjects who did not participate in the exogenous-distribution experiment were allowed to participate. 24 subjects participated in a session and each session was separated into two matching groups of 12 running on separate servers. For each treatment, two sessions (i.e. four matching groups) were run. Sessions took less than 1 hour and 30 minutes, and on average subjects earned between $€ 13$ and $€ 20 .{ }^{19}$ As in the exogenousdistribution experiment, a session consisted of ten bargaining rounds.

In order to give subjects experience in bargaining under risk with a residual claimant, they bargained over exogenously specified distributions in the first five rounds. ${ }^{20}$ In rounds 6 through 10, at the beginning of each round, the residual claimant was given two possible distributions of pies and asked to choose one of them which would be implemented, either with certainty in the transparent choice treatment, or with $70 \%$ chance in the non-transparent choice treatment (cf. Figure 5).

All of the other procedures remained the same as in exogenous-distribution design. ${ }^{21} \mathrm{In}$ each bargaining round, subjects had four minutes to reach an agreement and communication was not allowed. Between rounds, subjects were randomly rematched within their matching group, but always kept their role as either a $\mathrm{RC}$ or a FP player. As before, after all ten bargaining rounds had been finished, subjects completed a risk elicitation task (see Figure A.1 of Appendix A and a series of survey questions, which included their judgements on fair allocations to the FP player.

\subsection{Results}

Table 4 gives an overview of the choices made by RC players during the last five periods, when they were asked to decide between two distributions over which to bargain. As can be seen from the table, subjects were generally reluctant to take the riskier of the two distributions, with overall two-thirds of choices being for the safer of the two. The Certain versus Tertiary alternative is the notable exception, with just over $50 \%$ of RC players choosing the riskier tertiary distribution. The significance of this result is established in the first regression of

\footnotetext{
${ }^{19}$ In the endogenous-choice sessions, the payment scheme for the risk-elicitation task was adjusted to avoid over-compensating this part. In the adjusted scheme, there was a 50-50 chance that a random decision was used for payment; if a random decision was not used, the subject received a fixed $€ 4$ for this part. As in the exogenous-choice sessions, subjects also received a $€ 2$ show-up fee in addition to their earnings from the bargaining and risk elicitation tasks. In both experiments subjects were not given instructions for the risk elicitation task until after the bargaining phase.

${ }^{20}$ The data from the first five rounds can be used to conduct robustness check of the results from the exogenous-distribution sessions. As with the transparency contrast, this robustness check is not a primary concern and so is relegated to the supplementary materials. All the main results from Section 2.3 carry over to the data from the first five rounds of the endogenous-distribution treatments - see Appendix D for details.

${ }^{21}$ The order of bargaining distributions was not changed across matching groups. As the order for these last five bargaining periods was fixed - since there was no obvious re-ordering as in the no choice case - the chosen order ensured that the distributions in period six were not the distributions in periods four or five.
} 
Table 5. The Certain versus Tertiary alternative is the baseline of this regression and the variables $\mathbf{1}[\cdot]$ are indicator variables assuming value 1 for the respective alternative and 0 otherwise. As can be seen from the table, for any alternative other than Certain versus Tertiary there is a significantly lower rate of riskier-distribution choice. Moreover, the effect is fairly uniform across the four indicator variables: it is not possible to reject the null hypothesis that all of the coefficients are all equal $(p=0.604) .{ }^{22}$ The second specification of Table 5 illustrates that this effect is not a result of the difference in risk - fixing the extremes of the distribution, the tertiary distributions are less risky than their binary counter-parts. ${ }^{23}$ Consequently, subjects appear most likely to prefer to bargain over a risky distribution, rather than the expected value for sure, when there is the possibility of an ex-post equal split.

Table 4: Percent of RCs Choosing Riskier Distribution (Periods 6-10)

\begin{tabular}{|c|c|c|c|}
\hline Alternatives & Low Risk & High Risk & Combined \\
\hline Certain versus Tertiary & 52.1 & 52.1 & 52.1 \\
\hline Certain versus Binary & 31.3 & 39.6 & 35.4 \\
\hline Tertiary versus Binary & 31.3 & 25.0 & 28.1 \\
\hline$(16,20,24)$ versus $(12,20,28)$ & 27.1 & 25.0 & 26.0 \\
\hline$(16,24)$ versus $(12,28)$ & 37.5 & 12.5 & 25.0 \\
\hline Pooled & 35.8 & 30.8 & 33.3 \\
\hline
\end{tabular}

The final regression of Table 5 addresses Hypothesis 5, which stated that the likelihood of choosing the risky distribution should increase in risk aversion of the RC player. Contrary to that prediction, the likelihood of choosing the riskier distribution is decreasing in the risk aversion of the RC player. While in contradiction to the theory-based hypothesis, it is entirely consistent with the results from the exogenous-distribution experiment, where it was the relatively less risk averse $\mathrm{RC}$ players that appeared to benefit from risk.

A summary of the bargaining outcomes and fairness assessments can be found in Table 6 . For the most part, the observations from the exogenous-distribution environment carry over to the endogenous one: ${ }^{24}$ final FP earnings and agreed FP payments are generally decreasing in the riskiness of the distribution; bargaining over a risky distribution results in more dis-

\footnotetext{
${ }^{22} \mathrm{~A}$ linear regression model is used to keep the regression analysis simple and consistent across tables, and for the ease of interpretation of coefficients. For specifications that only include a complete set of indicators as independent variables, such as specification (1) of Table 5, this simplification is not important. This is not necessarily the case for specifications with independent variables that are not of this form. However, using a logit or probit model does not change the conclusions for specifications (2) and (3) of Table 5; the same is also true for the disagreements regression of Table 10. These additional robustness checks are included in the data-analysis scripts of the supplementary materials.

${ }^{23}$ The Difference in Variance variable is normalised, so that the largest difference (certain versus $(12,28)$ ) is set to one. The tertiary-rather-than-risk-difference result can also be seen by comparing the proportion choosing $(12,20,28)$ over $(20)$ with the proportion choosing $(16,24)$ over $(20)$, since the former is riskier than the latter. In the sample included in the regression analysis, the difference is significant at the $5 \%$ level $(p=0.031$; including observations involving subjects with $|\rho| \geq 1$ it is significant at the $10 \%$ level $(p=0.077)$.

${ }^{24}$ See Table A.2 of Appendix A for a complete set of pairwise comparisons across distributions.
} 
Table 5: Linear Random-Effects Regression of Choice of Distribution (Periods 6-10)

\begin{tabular}{|c|c|c|c|}
\hline & \multicolumn{3}{|c|}{ Riskier Distribution Chosen } \\
\hline & (1) & $(2)$ & $(3)$ \\
\hline $\mathbf{1}$ [Certain versus Binary] & $-0.20^{* * *}(0.068)$ & & \\
\hline $\mathbf{1}[$ Tertiary versus Binary] & $-0.26^{* * *}(0.050)$ & & \\
\hline $\mathbf{1}[(16,20,24)$ versus $(12,20,28)]$ & $-0.29^{* * *}(0.050)$ & & \\
\hline $\mathbf{1}[(16,24)$ versus $(12,28)]$ & $-0.29^{* * *}(0.058)$ & & \\
\hline Difference in Variance & & $0.05 \quad(0.075)$ & \\
\hline $\mathbf{1}[$ Certain versus Tertiary] & & $0.26^{* * *}(0.039)$ & $0.26^{* * *}(0.039)$ \\
\hline$\rho_{R C}$ & & & $-0.21^{* * *}(0.076)$ \\
\hline Constant & $0.54^{* * *}(0.041)$ & $0.25^{* * *}(0.036)$ & $0.34^{* * *}(0.035)$ \\
\hline $\mathrm{R}^{2}$ & 0.05 & 0.05 & 0.06 \\
\hline Observations & 455 & 455 & 455 \\
\hline
\end{tabular}

Notes: Data includes only observations for which $\left|\rho_{R C}\right|<1 .{ }^{* * *} 1 \%,{ }^{* *} 5 \%,{ }^{*} 10 \%$ significance using standard errors clustered at the matching group level. In (1), Certain versus Tertiary is the baseline category. Difference in Variance variable normalized so that the largest difference (Certain versus $(12,28)$ ) is 1 .

agreements and longer bargaining duration; and agreed FP payments for risky distributions tend to lie between the (self-serving) fairness assessments of the FP and RC players.

Regression analyses corroborate this impression. In the first regression of Table 7 it can be seen that agreed FP payments are, in accordance with Hypothesis 1, (weakly) decreasing as risk increases. An analogous linear regression, specification (1), for disagreements establishes the significance of the increase in the frequency of disagreements for most risky distributions, contrary to Hypothesis 4. The second specifications show that the riskier of the two distributions being implemented does not have a significant bearing on agreed payments to the FP player, but does increase the likelihood of disagreement. ${ }^{25}$ This suggests that choosing the riskier distribution may have a cost that is not captured by the theory, which assumes no disagreements. Finally, specification (3) establishes that the majority of the comparative statics from Hypothesis 2 carry over to the endogenous-distribution environment. For a given distribution, the direct effect of more risk averse is to reduce bargaining power (negative effect on payments for FP players; positive for RC players). For RCs, the interaction between variance and risk aversion improves their bargaining position. However, the direct effect is smaller and the interaction effect larger than in the exogenous-distribution environment, resulting an overall effect for $\rho_{R C}$ that is negative for risky distributions; i.e. more risk aversion improves the RC player's bargaining position, contrary to Hypothesis 2 .

Finally, Table 8 provides further evidence for the consistency with which the estimates of risk preferences organise the results of bargaining outcomes, although these are not always in line with the benchmark theory. The first regression replicates the certainty equivalent analysis of Table 3. As in the exogenous-distribution sessions, but contrary to Hypothesis 3 ,

\footnotetext{
${ }^{25}$ The linear functional form slightly over-states the disagreement effect in this case. With either a logit or probit form the marginal effect is around $5.5 \%$, and the significance between $5-7 \%$.
} 
Table 6: Bargaining Outcomes and Fairness Perceptions in the Endogenous Environment (Periods 6-10)

\begin{tabular}{|c|c|c|c|c|c|c|}
\hline \multirow{2}{*}{$\begin{array}{l}\text { Distribution } \\
\text { of Pie }\end{array}$} & \multirow{2}{*}{$\begin{array}{c}\text { Final FP } \\
\text { Earnings }(€) \\
\end{array}$} & \multirow{2}{*}{$\begin{array}{c}\text { Agreed FP } \\
\text { Payments }(€)\end{array}$} & \multirow{2}{*}{$\begin{array}{c}\text { Disagreements } \\
(\%) \\
\end{array}$} & \multirow{2}{*}{$\begin{array}{l}\text { Remaining } \\
\text { Time (sec) } \\
\end{array}$} & \multicolumn{2}{|c|}{ Fair Payment to FP } \\
\hline & & & & & $\mathrm{FP}(€)$ & $\mathrm{RC}(€)$ \\
\hline$(20)$ & 9.74 & 10.14 & 3.9 & 119 & 10.02 & 10.10 \\
\hline$(16,20,24)$ & 8.39 & 9.77 & 14.1 & 62 & 10.45 & 9.78 \\
\hline$(16,24)$ & 8.71 & 9.79 & 11.2 & 55 & 10.19 & 9.20 \\
\hline$(12,20,28)$ & 8.51 & 9.23 & 7.4 & 51 & 9.85 & 8.66 \\
\hline$(12,28)$ & 7.47 & 8.69 & 12.4 & 29 & 9.58 & 8.56 \\
\hline
\end{tabular}

Table 7: Linear Random-Effects Regressions of Bargaining Outcomes in the Endogenous Environment (Periods 6-10)

\begin{tabular}{|c|c|c|c|c|c|}
\hline \multirow[b]{3}{*}{$\mathbf{1}[(16,20,24)]$} & \multicolumn{3}{|c|}{ Agreed FP Payments } & \multicolumn{2}{|c|}{ Disagreements } \\
\hline & $(1)$ & $(2)$ & $(3)$ & $(1)$ & $(2)$ \\
\hline & $-0.39^{* *} \quad(0.153)$ & & & $0.12^{* *}(0.048)$ & $0.11^{* *}(0.050)$ \\
\hline $\mathbf{1}[(16,24)]$ & $-0.39^{* *} \quad(0.197)$ & & & $0.07^{* *}(0.033)$ & $0.04 \quad(0.034)$ \\
\hline $\mathbf{1}[(12,20,28)]$ & $-0.90^{* * *}(0.319)$ & & & $0.04 \quad(0.039)$ & $-0.02 \quad(0.043)$ \\
\hline $\mathbf{1}[(12,28)]$ & $-1.47^{* * *}(0.337)$ & & & $0.10^{* *}(0.047)$ & $(0.070)$ \\
\hline Variance & & $-1.47^{* * *}(0.447)$ & $-0.96^{*} \quad(0.529)$ & & \\
\hline 1[Riskier Dist.] & & $0.09 \quad(0.255)$ & $0.04 \quad(0.246)$ & & $0.08^{* *}(0.040)$ \\
\hline$\rho_{F P}$ & & & $-1.35^{* *}(0.562)$ & & \\
\hline$\rho_{R C}$ & & & $0.28 \quad(0.361)$ & & \\
\hline$\rho_{R C} \times \operatorname{Var}$ & & & $-1.73^{* *}(0.731)$ & & \\
\hline Constant & $10.22^{* * *}(0.163)$ & $10.17^{* * *}(0.119)$ & $10.59^{* * *}(0.341)$ & $0.03^{* *}(0.017)$ & $0.03^{*}(0.017)$ \\
\hline $\mathrm{R}^{2}$ & 0.07 & 0.07 & 0.11 & 0.02 & 0.04 \\
\hline Observations & 371 & 371 & 371 & 412 & 412 \\
\hline
\end{tabular}

Notes: Data includes only observations for which $\left|\rho_{i}\right|<1$ for both RC and FP players. ${ }^{* * *} 1 \%,{ }^{* *} 5 \%$, ${ }^{*} 10 \%$ significance using standard errors clustered at the matching group level.

the estimated certainty equivalent for RC players is decreasing in the their estimated $\rho$ (see specification (1)). ${ }^{26}$ Specifications (2) and (3) look at periods 1-5 where players could not choose the distribution. The results of specification (2) show that the relatively less risk averse RC players do significantly better with risk, and specification (3) shows that the relatively more risk averse do worse. Consistent with these results, one can see from the last column of Table 3, that in periods $6-10$ it is the less risk averse RC players who have a higher likelihood to choose the riskier distribution.

\section{Bargaining Process}

Our analysis thus far has focussed on bargaining outcomes, primarily because these are objects over which our benchmark theory provides predictions. Next we turn our attention to

\footnotetext{
${ }^{26}$ Although neither $\left.\mathbf{1}\left[\rho_{R C}>\rho_{F P}\right]\right)$ nor $\mathbf{1}[$ Var. $>0] \times \mathbf{1}\left[\rho_{R C}>\rho_{F P}\right]$ are significant (at $5 \%$ level) in isolation, the overall effect of the RC player being more risk averse than the FP player when there is risk is significant.
} 
Table 8: Linear Random-Effects Regression of the Certainty Equivalent of Agreements for RC Players and Riskier Distribution Choice in the Endogenous Environment

\begin{tabular}{|c|c|c|c|c|}
\hline & $\begin{array}{l}\text { Certainty Equ } \\
\text { (1) }\end{array}$ & $\begin{array}{l}\text { alent of Agreemen } \\
(2)\end{array}$ & $\begin{array}{c}\text { t for RC Player } \\
(3)\end{array}$ & $\begin{array}{c}\text { Riskier Chosen } \\
\text { (1) }\end{array}$ \\
\hline $\mathbf{1}[$ Var. $>0]$ & $\overline{0.68^{* * *}(0.147)}$ & $1.29^{* * *}(0.317)$ & $\overline{-1.00^{* *}(0.457)}$ & \\
\hline $\mathbf{1}\left[\rho_{R C}>\rho_{F P}\right]$ & $-0.45 \quad(0.367)$ & & & \\
\hline $\mathbf{1}[$ Var. $>0] \times \mathbf{1}\left[\rho_{R C}>\rho_{F P}\right]$ & $-0.53^{*} \quad(0.318)$ & & & \\
\hline $\mathbf{1}\left[\rho_{R C} \leq .5\right]$ & & & & $0.13^{* *}(0.052)$ \\
\hline Constant & $9.75^{* * *}(0.148)$ & $8.89^{* * *}(0.327)$ & $10.29^{* * *}(0.251)$ & $0.22^{* * *}(0.047)$ \\
\hline $\mathrm{R}^{2}$ & 0.05 & 0.05 & 0.03 & 0.02 \\
\hline Observations & 749 & 281 & 97 & 412 \\
\hline Periods & $1-10$ & $1-5$ & $1-5$ & $6-10$ \\
\hline RC sub-sample & - & $\rho_{R C} \leq 0.5$ & $\rho_{R C}>0.5$ & - \\
\hline
\end{tabular}

Notes: Data includes only observations for which $\left|\rho_{i}\right|<1$ for both RC and FP players. ${ }^{* * *} 1 \%,{ }^{* *} 5 \%,{ }^{*} 10 \%$ significance using standard errors clustered at the matching group level.

the bargaining process data on which the theory is silent. The unstructured design provides a rich data set on offers, and the timing and the sequence of these offers. These data can provide further insights into the nature of bargaining conflicts, how these conflicts are resolved, and the possible explanations for the deviations we observe from the benchmark theory. For this analysis, we pool the data from the exogenous and endogenous distribution sessions, and investigate in turn offers, concessions and duration.

The overall picture, which is consistent with our analysis of outcomes, is one in which the presence of risk increases conflict, in a large part because of differences in perceptions of what constitutes a fair division. Further, the presence of risk seems to lead to notably different bargaining postures by the FP and RC players. For example, when there is risk, FP players generally make larger concessions, while RC players make smaller concessions. Finally, risk attitudes - particularly for FP players - play an important role. Specifically, more risk averse FP players are less aggressive from the start of bargaining, make larger concessions and are more likely to accept the RC's offer than are less risk averse FP players. These observations go a long way to explain why it is actually the comparatively less risk averse residual claimants who seem to benefit from bargaining over a risky pie. The reason is that such residual claimants are more likely to be paired with a comparatively more risk averse fixed-payoff player, and that such players appear to be in a "weak" bargaining position.

\subsection{Offers}

Despite not being fully credible, as they can always be revised, it is still informative to compare the opening offers of the two types of players with their fairness assessments and final offers (offers outstanding either at the time of agreement or the expiry of bargaining time). These data are summarized in Table 9 . It should be of little surprise to see that the 
Table 9: Opening and Final Offers by Player Type

\begin{tabular}{|c|c|c|c|c|c|c|}
\hline \multirow{2}{*}{$\begin{array}{l}\text { Distribution } \\
\text { of Pie }\end{array}$} & \multicolumn{2}{|c|}{ Opening Offers } & \multicolumn{2}{|c|}{ Final Offers } & \multicolumn{2}{|c|}{ Fair Payoff to FP } \\
\hline & $\mathrm{FP}$ & $\mathrm{RC}$ & FP & $\mathrm{RC}$ & $\mathrm{FP}$ & $\mathrm{RC}$ \\
\hline$(20)$ & 12.67 & $8.23^{* * *}$ & 11.25 & $9.59^{* * *}$ & 9.91 & 10.16 \\
\hline$(16,20,24)$ & 12.74 & $6.86^{* * *}$ & 10.69 & $8.67^{* * *}$ & 10.39 & 9.70 \\
\hline$(16,24)$ & 12.48 & $7.03^{* * *}$ & 10.64 & $8.80^{* * *}$ & 10.21 & 9.27 \\
\hline$(12,20,28)$ & 11.16 & $5.78^{* * *}$ & 9.81 & $7.79^{* * *}$ & 9.82 & 8.64 \\
\hline$(12,28)$ & 10.97 & $5.84^{* * *}$ & 9.43 & $7.63^{* * *}$ & 9.54 & 8.40 \\
\hline
\end{tabular}

Notes: The lightly shaded cells are significantly different from $(20)$ at the $1 \%$ level. ${ }^{* * *}$ indicates that the offers between RCs and FPs are significantly different at the $1 \%$ level.

opening offers of the RC players are always significantly lower than those of the FP player. Consistent with Bolton and Karagözoğlu (2013), opening offers are also more extreme than subjects' reported fair allocation. Moreover, RC players always demand a risk premium whenever they are exposed to risk, and this premium is increasing in the riskiness of the distribution. While FP players also tended to demand less as risk increases, their opening offers are consistently above half the expected pie size.

The two middle columns of Table 9 show a similar pattern for final offers. Both the $\mathrm{RC}$ and FP players concede ground from their opening positions; although, RC players still demand a statistically significant risk premium, relative to the certain distribution, for all the risky distributions. While the final offer of RCs is still significantly lower than that of the FP players, the average difference is now only $€ 1.74$, as compared to $€ 3.71$ for opening offers. Note, however, that final offers by RC players would still give less to the FP player than their own fair assessment. The final offers of FP players concede a statistically significant risk premium, relative to the certain distribution, to the $\mathrm{RC}$ player for all the risky distributions, unlike with opening offers where this was only the case for the two riskiest distributions. Indeed, for these two distributions, their final offers are actually slightly less than their perceived fair allocation. Therefore, it seems that there is broad agreement that the residual claimant should be compensated for her exposure to risk, but that the tension in bargaining is to determine precisely the magnitude of compensation.

Interestingly, regressing opening offers on fairness perceptions, while controlling for the riskiness of the distribution, reveals that opening offers are significantly positively correlated with fairness perceptions for FP players (coefficient $=0.16, p<0.01$ ). However, for RC players there is no such relationship between fairness perceptions and opening offers (coefficient $=0.02, p>0.7$ ). For final offers, the results are nearly identical for FP player (coefficient $=0.15, p<0.01)$, while for RC players, the relationship is still not significant $(p=0.13)$, but the coefficient has increased (0.13) in magnitude. Thus, at least for FP players, own fairness perceptions are positively related to the offers made.

With these summary statistics in mind, Table 10 investigates offers in more detail. The 
first two columns show that opening offers are strongly influenced by one's risk preferences. ${ }^{27}$ As can be seen, the more risk averse is the FP player, the lower is his opening demand, while the more risk averse the RC player is, the less is her opening offer to the FP player. Thus, one piece of the picture emerges: the more risk averse are FP players, the less they demand from the start of bargaining. The table also shows that more risk averse RC players actually demand greater compensation for their exposure to risk; that is, in contrast to FP players, they become more aggressive in their opening offers.

Table 10: Linear Random-Effects Regressions of the Role of Risk Preferences and Offers

\begin{tabular}{|c|c|c|c|c|}
\hline & \multicolumn{2}{|c|}{ Opening Offer } & \multirow{2}{*}{$\begin{array}{l}\text { Agreed FP } \\
\text { Payments }\end{array}$} & \multirow[t]{2}{*}{ Disagreements } \\
\hline & $\mathrm{FP}$ & $\mathrm{RC}$ & & \\
\hline $\mathbf{1}[(16,20,24)]$ & $-0.03 \quad(0.216)$ & $-1.34^{* * *}(0.245)$ & $-0.52^{* * *}(0.176)$ & $0.06^{*} \quad(0.032)$ \\
\hline $\mathbf{1}[(16,24)]$ & $-0.23 \quad(0.236)$ & $-1.21^{* * *}(0.216)$ & $-0.50^{* * *}(0.174)$ & $0.06^{* *}(0.029)$ \\
\hline $\mathbf{1}[(12,20,28)]$ & $-1.50^{* * *}(0.241)$ & $-2.43^{* * *}(0.223)$ & $-0.64^{* * *}(0.179)$ & $0.02 \quad(0.035)$ \\
\hline $\mathbf{1}[(12,28)]$ & $-1.68^{* * *}(0.258)$ & $-2.34^{* * *}(0.230)$ & $-0.92^{* * *}(0.179)$ & $0.09^{* * *}(0.031)$ \\
\hline$\rho_{F P}$ & $-1.24^{* *}(0.573)$ & & $-1.18^{* * *}(0.352)$ & $-0.18^{* * *}(0.049)$ \\
\hline$\rho_{R C}$ & & $-1.51^{* * *}(0.273)$ & $-0.19 \quad(0.219)$ & $-0.07^{* *}(0.031)$ \\
\hline Opening offer FP & & & $0.22^{* * *}(0.040)$ & $0.02^{* * *}(0.005)$ \\
\hline Opening offer RC & & & $0.16^{* * *}(0.039)$ & $-0.01^{* *}(0.005)$ \\
\hline$\left(\right.$ Time $1^{\text {st }}$ offer FP) $/ 100$ & & & $0.35 \quad(0.227)$ & $0.01 \quad(0.030)$ \\
\hline$\left(\right.$ Time $1^{\text {st }}$ offer RC) $/ 100$ & & & $(0.166)$ & $(0.072)$ \\
\hline$\Delta\left(\right.$ Time $1^{\text {st }}-2^{\text {nd }}$ offer FP $) / 100$ & & & $(0.155)$ & $(0.039)$ \\
\hline$\Delta\left(\right.$ Time $1^{\text {st }}-2^{\text {nd }}$ offer $\left.\mathrm{RC}\right) / 100$ & & & $-0.20 \quad(0.184)$ & $(0.030)$ \\
\hline Constant & $13.11^{* * *}(0.296)$ & $8.70^{* * *}(0.214)$ & $6.79^{* * *}(0.728)$ & $(0.073)$ \\
\hline$R^{2}$ & 0.13 & 0.12 & 0.24 & 0.08 \\
\hline Observations & 1046 & 1080 & 1536 & 1736 \\
\hline
\end{tabular}

Notes: Data includes only observations for which $\left|\rho_{i}\right|<1$ for both $\mathrm{RC}$ and $\mathrm{FP}$ players. ${ }^{* * *} 1 \%,{ }^{* *} 5 \%,{ }^{*} 10 \%$ significance using standard errors clustered at the matching group level.

Of course, if opening offers are merely cheap talk, then the above results would be of little importance. However, it has been suggested by Galinsky and Mussweiler (2001) that opening offers may anchor negotiations and influence the final outcome. As can be seen, in the third column of Table 10, there is a significantly positive relationship between the opening offer of both the FP and RC players and the final agreed upon payment to the FP player. Therefore, an FP player who demands more, or an RC player who offers less, as an initial offer is likely to end up with a more favorable outcome, assuming an agreement can be reached. This finding represents another important piece of the picture: making a weak opening offer - which is more likely to be done by more risk averse FP players - leads to a lower payment.

When we look at concessions, we will show that this result appears to be due to the persistence of anchoring throughout the bargaining process. However, before proceeding, a word of caution is in order. While strong opening offers increase the payoff to the player

\footnotetext{
${ }^{27}$ The table does not include fairness perceptions as an explanatory variable; however, when adding it there is no qualitative difference in the results.
} 
making the offer, conditional on an agreement being reached, the more extreme is the opening offer, the greater the chance of disagreement. This is evidenced in the right-most column of Table 10 where there is a significantly positive coefficient on the opening offer of the FP player and a significantly negative coefficient on the opening offer of the RC player. ${ }^{28}$

Finally, the third and fourth columns of Table 10 also show that neither the time at which players made their first offer, nor the amount of time that they waited between making their first and second offer appeared to influence either the outcome, conditional on an agreement, or the likelihood of disagreement. These two variables are meant to capture aspects of a player's bargaining posture. For example, someone who makes an opening offer but then never amends it may be trying to "stick to his guns". However, as can be seen, there is no apparent effect for these variables.

\subsection{Concessions}

Table 11 looks at the process of concessions during bargaining (Panel (a)) and on whether the residual claimant accepts or not (Panel (b)). Consider first the concessions models. The dependent variable is the size of the concession from the current to the previous offer. The explanatory variables are the opponent's most recent concession, the current offer of the opponent, one's own previous offer, fairness perceptions, bargaining time, whether the pie is risky and the risk preferences of the players. As can be seen by the coefficient on the indicator for the presence of risk, FP players make larger concessions when the pie is risky, while RC players make smaller concessions. Thus, consistent with the explanation so far, FP players appear to adopt more concessionary bargaining positions when risk is present. This is further reinforced by the finding that more risk averse FP players also make greater concessions.

As can be seen by the positive coefficient on the variable "other's concession" for both player types, concessions appear to be reciprocal. That is, the larger my match's most recent concession, the larger is my own concession. The coefficient on the other's current offer shows that anchoring is important throughout bargaining. Specifically, for FP players, the more the RC player is offering, the less he is willing to concede. Similarly, for RC player, the more the FP player is demanding, the more she is willing to concede. Consistent with our earlier result, fairness perceptions seem more salient for FP players. The higher is his own perceived fair allocation, the less he is willing to concede. For RC players, the effect has the same direction, but is not significant.

In Table 11(b), the dependent variable is an indicator that takes value 1 if the $\mathrm{RC}$ player was the one that accepted. The main point to note is the negative, and weakly significant, coefficient on the risk coefficient of the FP player. Thus, the more risk averse the FP player, the more likely it is that the FP player is the one that ultimately accepts, again suggesting that such FP players are in a weak bargaining position. Finally, there is also the intuitive

\footnotetext{
${ }^{28}$ Recall that, for the RC player, making a higher offer is more generous to the FP player.
} 
Table 11: Linear Random-Effects Regression on Concessions Behaviour and Acceptances

(a) Concessions

\begin{tabular}{|c|c|c|}
\hline & FP Player & RC Player \\
\hline Other's Concession & $0.11^{* * *}(0.039)$ & $0.18^{* * *}(0.058)$ \\
\hline Other's Current Offer & $-0.06^{* * *}(0.017)$ & $0.04^{* *} \quad(0.019)$ \\
\hline Own Previous Offer & $0.35^{* * *}(0.036)$ & $-0.54^{* * *}(0.053)$ \\
\hline Fairness Perception & $-0.10^{* *} \quad(0.041)$ & $0.08 \quad(0.051)$ \\
\hline Time/100 & $0.09^{* *}(0.041)$ & $0.35^{* * *}(0.058)$ \\
\hline $\mathbf{1}[$ Var. $>0]$ & $0.51^{* * *}(0.159)$ & $-0.47^{* * *}(0.114)$ \\
\hline$\rho_{F P}$ & $0.79^{* *}(0.324)$ & \\
\hline$\rho_{R C}$ & & $-0.17 \quad(0.310)$ \\
\hline Constant & $-2.99^{* * *}(0.697)$ & $3.00^{* * *}(0.608)$ \\
\hline$R^{2}$ & 0.20 & 0.22 \\
\hline Observations & 3128 & 3482 \\
\hline
\end{tabular}

(b) Residual Claimant Accepts

\begin{tabular}{|c|c|}
\hline & RC Accepts \\
\hline $\mathbf{1}[$ Var. $>0]$ & $-0.02 \quad(0.034)$ \\
\hline$\rho_{F P}$ & $-0.16^{*} \quad(0.083)$ \\
\hline$\rho_{R C}$ & $0.07 \quad(0.067)$ \\
\hline Final Offer RC & $-0.05^{* * *}(0.010)$ \\
\hline Final Offer FP & $-0.03^{* *} \quad(0.011)$ \\
\hline Constant & $1.25^{* * *}(0.177)$ \\
\hline$R^{2}$ & 0.07 \\
\hline Observations & 844 \\
\hline
\end{tabular}

Notes: FP = Fixed-payoff player; RC $=$ Residual claimant. Data includes only observations for which $\left|\rho_{i}\right|<1$ for both $\mathrm{RC}$ and FP players. ${ }^{* *} 1 \%,{ }^{* *} 5 \%,{ }^{*} 10 \%$ significance using standard errors clustered at the matching group level.

result that $\mathrm{RC}$ players are less likely to accept when the final offers on the table, by both players, are more advantageous to the FP player.

\subsection{Duration}

To complete the overall picture of the bargaining process, we now look at the determinants of bargaining duration. Table 12 reports the results of a Weibull regression, where a player accepting an offer counts as a "failure" in the language of duration models. The regression includes a set of time-invariant explanatory variables, namely, the risk preferences of the FP and RC players, and an indicator variable for whether the pie is risky. The amount of bargaining conflict (the difference between the current offers of the FP and RC players) is also included, which is a time-varying coefficient. Note that a negative coefficient estimate means that the particular variable increases duration (i.e., bargaining takes longer), while positive coefficients mean that the variable decreases duration (i.e., bargaining ends sooner).

As can be seen from the first column, the amount of conflict has a strongly significant effect on duration. In particular, the greater the conflict, the longer that bargaining takes. Also consistent with our descriptive results, bargaining takes longer when the pie is risky. Interestingly, when the conflict variable is interacted with an indicator for risk, we see that the primary effect of risk on duration is through conflict. That is, when the pie is risky, for the same conflict, it simply takes longer for players to bridge their differences and come to an agreement, if they agree at all.

Finally, as further support for our claim that FP players — particularly the more risk averse ones - adopt weak bargaining positions, the duration decreases in the risk aversion of the FP player. This observation is consistent with that from Table 11(b), which showed 
that more risk averse FP players are more likely to accept the offer. The duration analysis shows that, in addition, they do so more quickly, perhaps because they fear disagreement.

Table 12: Weibull Regression on Bargaining Duration

\begin{tabular}{|c|c|c|}
\hline \multirow{4}{*}{$\begin{array}{l}\text { Conflict } \\
\mathbf{1}[\text { Var. }>0] \\
\mathbf{1}[\text { Var. }>0] \times \text { Conflict }\end{array}$} & \multicolumn{2}{|c|}{ Duration } \\
\hline & $-0.27^{* * *}(0.031)$ & $-0.17^{* * *}(0.043)$ \\
\hline & $-0.34^{* * *}(0.091)$ & $-0.08 \quad(0.136)$ \\
\hline & & $-0.16^{* * *}(0.056)$ \\
\hline$\rho_{F P}$ & $0.46^{* * *}(0.170)$ & $0.44^{* *}(0.176)$ \\
\hline$\rho_{R C}$ & $-0.07 \quad(0.138)$ & $-0.07 \quad(0.139)$ \\
\hline Constant & $-11.61^{* * *}(1.577)$ & $11.62^{* * *}(1.526)$ \\
\hline Log-Likelihoo & -618.85 & -609.63 \\
\hline Observations & 8532 & 8532 \\
\hline
\end{tabular}

Notes: Data includes only observations for which $\left|\rho_{i}\right|<1$ for both RC and FP players. ${ }^{* * *} 1 \%,{ }^{* *} 5 \%,{ }^{*} 10 \%$ significance using standard errors clustered at the matching-group level. In the Weibull regression, an acceptance is a "hit".

\section{Conclusion}

In this paper we experimentally study the effect of asymmetric exposure to risk in bargaining. Our results confirm many aspects of benchmark theoretical predictions: risk-exposed residual claimants are generally able to extract a risk premium from the fixed-payoff player and the premium is increasing in the riskiness of the distribution. Further, in a number of cases this premium is large enough to make it advantageous (in expected utility terms) for residual claimants to bargain with some ex-post risk. That is, we find empirical support for the at first sight counter-intuitive prediction from theory that the strategic benefit can outweigh the direct cost of ex-post risk.

We also identify some behavioral aspects that go, in part, against the benchmark theory. First, disagreement is significantly more likely when bargaining is over a risky distribution than when it is over a risk-free distribution - with disagreements occurring only $5 \%$ of the time under the risk-free distribution but nearly $20 \%$ of the time with the riskiest distribution. This observation is consistent with the idea that risk introduces competing (self-serving) norms for fairness that increase bargaining conflict. With no risk, the 50-50 norm is the most salient and most agreements specify this division. However, as risk increases, differences in fairness perceptions emerge and grow. Second, empirically it is the less risk averse residual claimants who benefit the most from risk, while theory predicts the opposite.

Further we find that, when given the choice, residual claimants generally prefer to bargain over a less risky distribution, except when choosing between the certain pie and a risky pie with the possibility for an ex-post equal split. This appears to be for good reason: already when the distribution of the pie is exogenous, disagreements occur more frequently with riskier distributions, and they are more likely to occur after choosing to bargain over the 
riskier distribution. That being said, we want to emphasize that some residual claimants do choose the riskier distribution. Our results not only show that it is the relatively less risk averse who are more willing to do so, but also suggest that it is this same group that subsequently benefit the most from it.

Since risk preferences are private information, fixed-payoff players may be willing to compensate an "average" residual claimant for her exposure to risk, thus over-compensating the relatively less risk averse ones (recall Figure 3(a), which showed that, for known risk preferences, compensation for risk is increasing in the risk aversion of the residual claimant). In addition, fixed-payoff players, in particular the more risk averse ones, adopt weak bargaining strategies with risky distributions, in that they demand less from the start, make larger concessions and are more likely to accept. These two factors, likely working in conjunction, can explain why the relatively less risk averse residual claimants benefit the most from risk exposure. This explanation suggests that explicitly modeling the incomplete information could reconcile the benchmark theory with our experimental evidence. However, simply adding incomplete information over the residual claimant's risk attitude is unlikely to be sufficient. In the benchmark model, while increased risk aversion implies greater compensation for risk, it also implies less bargaining power. We know that a residual claimant would not pretend to be more risk averse than she is (recall Figure 3(b)). In fact, it would be advantageous to be seen to be risk neutral. Another important aspect of our results is that bargaining frictions increase with riskiness of the distribution and that this is - at least in part - the result of diverging fairness ideals between the fixed-payoff player and the residual claimant. Consequently, a satisfactory extension of the theory would require some separation between the determinants of bargaining power and the determinants of fair compensation for risk exposure. $^{29}$

Our results also illustrate the promise of the implemented experimental framework to understand bargaining behavior and frictions more generally. For example, settings where asymmetric exposure to risk may play an even greater role include dynamic bargaining environments, where agents must interact repeatedly and must periodically negotiate the split of a pie. In this case, not only are there competing norms of fairness in any given bargaining period, but also the ex-post allocation from one period may influence the agents' views on what is fair in the next period. A concrete example in the field concerns North American automakers and their labor unions. During the financial crisis of 2008, on the verge of bankruptcy, the automakers extracted large concessions from their unions. However, in subsequent years, the automakers have been more profitable than anticipated. Not surprisingly, the unions want "pay back" for their past sacrifices, while automakers claim that this

\footnotetext{
${ }^{29}$ The model of Abreu et al. (2012) is a recent example in this direction, where the uncertainty over the reputational/behavioural perturbations is separate from the underlying uncertainty over preference parameters, which, in their case, is the discount rate. For a recent attempt to explicitly incorporate fairness ideals in a bargaining model, see Birkeland and Tungodden (2014).
} 
is "the new normal". The following quote about recent negotiations between the Canadian Autoworkers Union and the automakers summarizes the bargaining positions, and competing fairness norms, very nicely: "[The automakers] also want wages to be more closely tied to profitability. That sets the stage for difficult bargaining, because the union is intent on raising wages and recovering some benefits they surrendered during the 2008-2009 auto crisis." 30 In follow-up work, preliminary experimental results lend support to the "pay back" hypothesis.

\section{References}

Abreu, Dilip, David Pearce, Ennio Stacchetti. 2012. One-sided uncertainty and delay in reputational bargaining. Unpublished manuscript 326.

Akbaş, Merve, Dan Ariely, Sevgi Yüksel. 2014. When is inequality fair? An experiment on the effect of procedural justice and agency. Working Paper.

Babcock, Linda, George Loewenstein, Samuel Issacharoff, Colin F. Camerer. 1995. Biased judgments of fairness in bargaining. American Economic Review 85(5) 1337-1343.

Birkeland, Sigbjørn, Bertil Tungodden. 2014. Fairness motivation in bargaining: A matter of principle. Theory and Decision 77(1) 125-151.

Bolton, Gary E., Emin Karagözoğlu. 2013. On the interaction of hard and soft bargaining leverage: A test of Schelling's hypothesis and a modified Zeuthen-Harsanyi model. Working Paper.

Brock, J. Michelle, Andreas Lange, Erkut Y. Ozbay. 2013. Dictating the risk: Experimental evidence on giving in risky environments. American Economic Review 103(1) 415-37.

Bruhin, Adrian, Helga Fehr-Duda, Thomas Epper. 2010. Risk and rationality: Uncovering heterogeneity in probability distortion. Econometrica 78(4) 1375-1412.

Cachon, Gérard P. 2004. The allocation of inventory risk in a supply chain: Push, pull, and advance-purchase discount contracts. Management Science 50(2) 222-238.

Cappelen, Alexander W., Astri Drange Hole, Erik Ø. Sørensen, Bertil Tungodden. 2007. The pluralism of fairness ideals: An experimental approach. American Economic Review 97(3) $818-827$.

Cettolin, Elena, Franziska Tausch. 2013. Risk taking and risk sharing: Does responsibility matter? Netspar Discussion Paper No. 08/2013-049.

\footnotetext{
30 "Auto makers tell union wage hikes won't happen," by Greg Keenan, The Globe and Mail, June 6, 2012.
} 
Croson, Rachel T.A. 1996. Information in ultimatum games: An experimental study. Journal of Economic Behavior \& Organization 30(2) 197-212.

Dana, Jason, Roberto Weber, Jason Kuang. 2007. Exploiting moral wiggle room: Experiments demonstrating an illusory preference for fairness. Economic Theory 33 67-80.

Deck, Cary, Amy Farmer. 2007. Bargaining over an uncertain value: Arbitration mechanisms compared. Journal of Law, Economics and Organization 23(3) 547-579.

Fischbacher, U. 2007. z-Tree: Zurich toolbox for ready-made economic experiments. Experimental Economics 10(2) 171-178.

Forsythe, Robert, John Kennan, Barry Sopher. 1991. An experimental analysis of strikes in bargaining games with one-sided private information. American Economic Review 81(1) $253-278$.

Fréchette, Guillaume R. 2012. Session-effects in the laboratory. Experimental Economics 15(3) 485-498.

Fudenberg, Drew, David K. Levine. 2012. Fairness, risk preferences and independence: Impossibility theorems. Journal of Economic Behavior \& Organization 81(2) 606-612.

Gächter, Simon, Arno Riedl. 2005. Moral property rights in bargaining with infeasible claims. Management Science 51(2) 249-264.

Galinsky, Adam D., Thomas Mussweiler. 2001. First offers as anchors: The role of perspective-taking and negotiator focus. Journal of Personality and Social Psychology 81(4) 657-669.

Greiner, B. 2004. An online recruitment system for economic experiments. K. Kremer, V. Macho, eds., Forschung und wissenschaftliches Rechnen. GDWG Bericht 63.

Karagözoğlu, Emin, Arno Riedl. 2014. Performance information, production uncertainty and subjective entitlements in bargaining. Management Science in press.

Kimball, Miles S. 1990. Precautionary saving in the small and in the large. Econometrica 58(1) 53-73.

Konow, James. 1996. A positive theory of economic fairness. Journal of Economic Behavior \& Organization 31(1) 13-35.

Konow, James. 2000. Fair shares: Accountability and cognitive dissonance in allocation decisions. American Economic Review 90(4) 1072-1091. 
Konow, James. 2001. Fair and square: The four sides of distributive justice. Journal of Economic Behavior \& Organization 46 137-164.

Lam, K.C., D. Wang, Patricia T.K. Lee, Y.T. Tsang. 2007. Modelling risk allocation decision in construction contracts. International Journal of Project Management 25 485-493.

Mitzkewitz, Michael, Rosemarie Nagel. 1993. Experimental reults on ultimatum games with incomplete information. International Journal of Game Theory 22(2) 171-198.

Murnighan, J. Keith, Alvin E. Roth, Françoise Schoumaker. 1987. Risk aversion and bargaining: Some preliminary results. European Economic Review 31(1-2) 265-271.

Rapoport, Amnon, James A. Sundali. 1996. Ultimatums in two-person bargaining with onesided uncertainty: Offer games. International Journal of Game Theory 25(4) 475-494.

Rapoport, Amnon, James A. Sundali, Darryl A. Seale. 1996. Ultimatums in two-person bargaining with one-sided uncertainty: Demand games. Journal of Economic Behavior 63 Organization 30(2) 173-196.

Riedl, Arno, Frans van Winden. 2012. Input versus output taxation in an experimental international economy. European Economic Review 56(2) 216-232.

Roth, Alvin E., Uriel Rothblum. 1982. Risk aversion and Nash's solution for bargaining games with risky outcomes. Econometrica 50(3) 639-647.

Rubinstein, Ariel. 1982. Perfect equilibrium in a bargaining model. Econometrica 50(1) 97-109.

White, Lucy. 2006. Prudence in bargaining: The effect of uncertainty on bargaining outcomes. Discussion Paper No. 5822.

White, Lucy. 2008. Prudence in bargaining: The effect of uncertainty on bargaining outcomes. Games and Economic Behavior 62(1) 211-231. 


\section{A Additional Material}

\section{A.1 Figures}

Figure A.1: Histogram: estimated CRRA risk aversion coefficients

(a) Exogenous Distribution Sessions

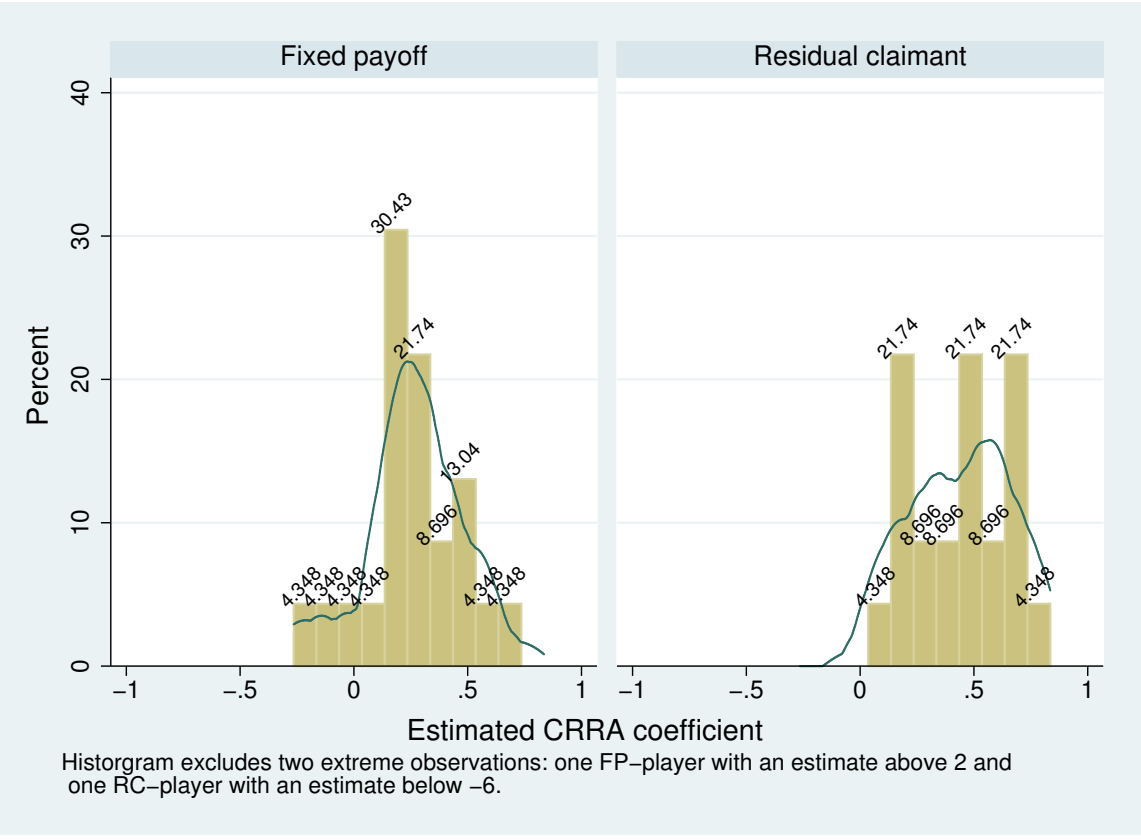

(b) Endogenous Distribution Sessions

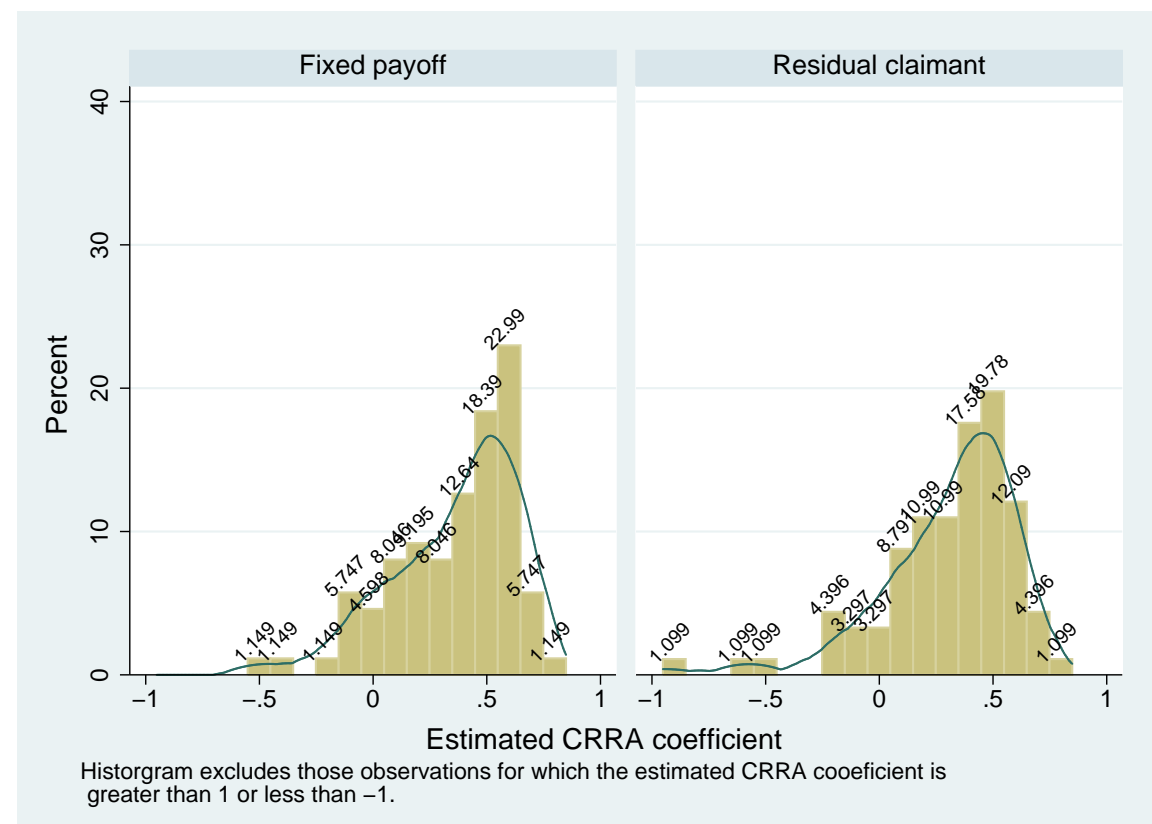




\section{A.2 Tables}

Table A.1: Pairwise Comparison of Bargaining Outcomes in the Exogenous Environment (Periods 1-10)

\begin{tabular}{|c|c|c|c|c|c|c|c|c|c|c|}
\hline & $(20)$ & $(16,20,24)$ & $(16,24)$ & $(12,20,28)$ & $(12,28)$ & $(20)$ & $(16,20,24)$ & $(16,24)$ & $(12,20,28)$ & $(12,28)$ \\
\hline & \multicolumn{5}{|c|}{ Final Earnings } & \multicolumn{5}{|c|}{ Agreed FP Payments } \\
\hline$(20)$ & 9.71 & $>$ & $>^{* *}$ & $>^{* * *}$ & $>^{* * *}$ & 10.16 & $>$ & $>^{* *}$ & $>^{* *}$ & $>^{* * *}$ \\
\hline$(16,20,24)$ & & 9.04 & $>^{* *}$ & $>^{* *}$ & $>^{* * *}$ & & 9.68 & $>$ & $>^{*}$ & $>^{* * *}$ \\
\hline$(16,24)$ & & & 8.17 & $>$ & $>^{*}$ & & & 9.61 & $>^{*}$ & $>^{* * *}$ \\
\hline$(12,20,28)$ & & & & 8.10 & $>^{* * *}$ & & & & 9.09 & $>$ \\
\hline \multirow[t]{2}{*}{$(12,28)$} & & & & & 7.14 & & & & & 8.80 \\
\hline & \multicolumn{5}{|c|}{ Disagreements } & \multicolumn{5}{|c|}{ Time Remaining } \\
\hline$(20)$ & 4.2 & $<$ & $<$ & $<$ & $<* * *$ & 151 & $>^{* * *}$ & $>^{* * *}$ & $>^{* * *}$ & $>^{* * *}$ \\
\hline$(16,20,24)$ & & 6.2 & $<$ & $<^{*}$ & $<* * *$ & & 70 & $>^{* * *}$ & $>^{*}$ & $>$ \\
\hline$(16,24)$ & & & 14.6 & $>$ & $<$ & & & 38 & $>$ & $<$ \\
\hline$(12,20,28)$ & & & & 10.4 & $<^{* *}$ & & & & 37 & $<$ \\
\hline$(12,28)$ & & & & & 18.8 & & & & & 53 \\
\hline
\end{tabular}

Notes: The symbol indicates how the outcome measure of the row distribution compares (statistically) to the column distribution. ${ }^{* * *} 1 \%,{ }^{* *} 5 \%,{ }^{*} 10 \%$ significance using standard errors clustered at the matching group level.

Table A.2: Pairwise Comparison of Bargaining Outcomes in the Endogenous Environment (Periods 6-10)

\begin{tabular}{|c|c|c|c|c|c|c|c|c|c|c|}
\hline & $(20)$ & $(16,20,24)$ & $(16,24)$ & $(12,20,28)$ & $(12,28)$ & $(20)$ & $(16,20,24)$ & $(16,24)$ & $(12,20,28)$ & $(12,28)$ \\
\hline & \multicolumn{5}{|c|}{ Final Earnings } & \multicolumn{5}{|c|}{ Agreed FP Payments } \\
\hline$(20)$ & 9.74 & $>^{* * *}$ & $>^{* *}$ & $>^{* * *}$ & $>^{* * *}$ & 10.14 & $>^{* *}$ & $>^{* *}$ & $>^{* * *}$ & $>^{* * *}$ \\
\hline$(16,20,24)$ & & 8.39 & $<$ & $<$ & $>$ & & 9.77 & $<$ & $>^{* *}$ & $>^{* * *}$ \\
\hline$(16,24)$ & & & 8.71 & $>$ & $>^{* *}$ & & & 9.79 & $>^{* *}$ & $>^{* * *}$ \\
\hline$(12,20,28)$ & & & & 8.51 & $>^{* *}$ & & & & 9.23 & $>^{* *}$ \\
\hline \multirow[t]{2}{*}{$(12,28)$} & & & & & 7.47 & & & & & 8.69 \\
\hline & \multicolumn{5}{|c|}{ Disagreements } & \multicolumn{5}{|c|}{ Time Remaining } \\
\hline$(20)$ & 3.9 & $<^{* *}$ & $<^{* *}$ & $<$ & $<^{* *}$ & 119 & $>^{* * *}$ & $>^{* * *}$ & $>^{* * *}$ & $>^{* * *}$ \\
\hline$(16,20,24)$ & & 14.1 & $>$ & $>$ & $>$ & & 62 & $>$ & $>$ & $>^{* *}$ \\
\hline$(16,24)$ & & & 11.2 & $>$ & $<$ & & & 55 & $>$ & $>^{* * *}$ \\
\hline$(12,20,28)$ & & & & 7.4 & $<$ & & & & 51 & $>^{* * *}$ \\
\hline$(12,28)$ & & & & & 12.4 & & & & & 29 \\
\hline
\end{tabular}

Notes: The symbol indicates how the outcome measure of the row distribution compares (statistically) to the column distribution. ${ }^{* * *} 1 \%,{ }^{* *} 5 \%,{ }^{*} 10 \%$ significance using standard errors clustered at the matching group level. 
Supplementary Materials: for Online Publication Only 


\section{B Sample Instructions}

\section{B.1 Exogenous Distribution}

\section{General Instructions}

\section{Welcome}

You are about to participate in a session on interactive decision-making. Thank you for agreeing to take part. The session should last about 90 minutes.

You should have already turned off all mobile phones, smart phones, mp3 players and all such devices by now. If not, please do so immediately. These devices must remain switched off throughout the session. Place them in your bag or on the floor besides you. Do not have them in your pocket or on the table in front of you.

The entire session, including all interaction between you and other participants, will take place through the computer. You are not allowed to talk or to communicate with other participants in any other way during the session. You are asked to follow these rules throughout the session. Should you fail to do so, we will have to exclude you from this (and future) session(s) and you will not receive any compensation for this session. We will start with a brief instruction period. Please read these instructions carefully. They are identical for all participants in this session with whom you will interact. If you have any questions about these instructions or at any other time during the experiment, then please raise your hand. One of the experimenters will come to answer your question.

\section{Structure of the session}

There are two parts to this session. Instructions for the part 1 are detailed below. Part 2 consists of survey and individual choice questions. Instructions for part 2 will be given once part 1 has been completed. Parts 1 and 2 are independent.

\section{Compensation for participation in this session}

You will be able to earn money for your decisions in both parts of this session. What you will earn from part 1 will depend on your decisions, the decisions of others and chance. Further details are given below. What you will earn from part 2 will only depend on your decisions and chance. Further details will be given after part 1 has been completed. In the instructions, and all decision tasks that follow, payoffs are reported in Euros (EUR). Your final payment will be 2 EUR plus the sum of your earnings from the two parts. Final payment takes place in cash at the end of the session. Your decisions and earnings in the session will remain anonymous. 


\section{Instructions for Part I}

\section{Structure of part 1}

Part 1 is structured as follows:

1. At the beginning of part 1, you will be randomly assigned as either a type A or a type B participant. Your type will remain the same for the duration of part 1.

2. Part 1 consists of 10 periods.

3. At the beginning of a period, you will be randomly paired with another participant of a different type. That is, if you were assigned as type A, you will be randomly paired with a participant that was assigned as type B; if you were assigned as type B, you will be randomly paired with a participant assigned as type A.

4. This random pairing procedure is repeated at the beginning of every period.

5. During the period, you will interact only with the participant you have been paired with for that period. We refer to this participant as your match.

\section{Description of a period}

6. During a period you and your match will negotiate over how to divide between you an amount of money. We call the amount of money that you have to divide the pie. However, you will not always know size of the pie for sure. In some periods, there will be only one value that the pie could be (i.e. it is certain), in others there will be two values it could be - with each amount equally likely - and in others there will be three values it could be - again, with each amount equally likely.

7. At the beginning of the period, you and your match will be informed of the list of possible amounts for the pie. This list will vary from period to period. Neither you nor your match will know the actual size of the pie until end of the period. Only at this point will the size of the pie be determined: it will be randomly selected from the list of possible amounts.

8. You will decide on how to divide the pie by negotiating over the value (in Euros) of a fixed payment to the type A participant. These negotiations will take place through the computer interface. You will have 4 minutes in which to negotiate. The time limit is binding: if you and your match do not reach an agreement during this time limit you will both receive zero for the period. 
9. During the negotiation time, you may make offers at any time. An offer is a suggested value for the fixed payment to the type A participant. Note: If you are a type $B$ participant, this will not be your payoff if the offer is accepted.

10. The only restrictions on the offers you can make are: 1) the offer must be larger than zero, and 2) the offer must be less than the smallest possible value for the size of the pie. The computer interface will ensure these restrictions are met. Finally, only the current offer, that is the most recent offer made by a participant, can be accepted by the other participant.

11. An agreement is reached when either you or your match accept the other's current offer. Once an offer has been accepted, negotiations for the period end.

12. If you do agree on a value for the fixed payment, then the payoff in this period for the type A participant will be the agreed payment. The type B participant will receive whatever is left from the pie once the agreed payment has been subtracted. Consequently, if you reach an agreement, type A's payoff will always be certain, whereas type B's payoff will depend on the realised size of the pie.

13. A period is ended either by an agreement or by the elapse of the negotiating time limit.

\section{At the end of a period}

14. At the end of a period, the random pie size, your payoff for the period and that of your match will be determined and displayed.

\section{The end of part 1}

15. After a period is finished, you will be randomly paired for a new period. Part 1 consists of 10 such periods.

16. At the end of part 1 - that is, after the tenth period - one period will be selected at random. The payoff you gained during the selected period will be used to as your final payoff for part 1 .

17. After your final payoff for part 1 has been calculated, the session will move on to part 2. Instructions for part 2 will be displayed on your computer terminal. Please read them carefully and proceed through part 2 at your own pace.

\section{Making and Accepting Offers}

\section{An example}


The following screen shot is used as an example to illustrate how you use the computer interface to make and accept offers. The screenshot shows the situation for a type A participant. The layout for a type B participant is analogous. For completeness, the associated screen for the type B participant is shown below.

Please note that the possible sizes of the pie, and the offers shown on the screen, are not values that you will see during the session itself. They have been selected for illustrative purposes only.

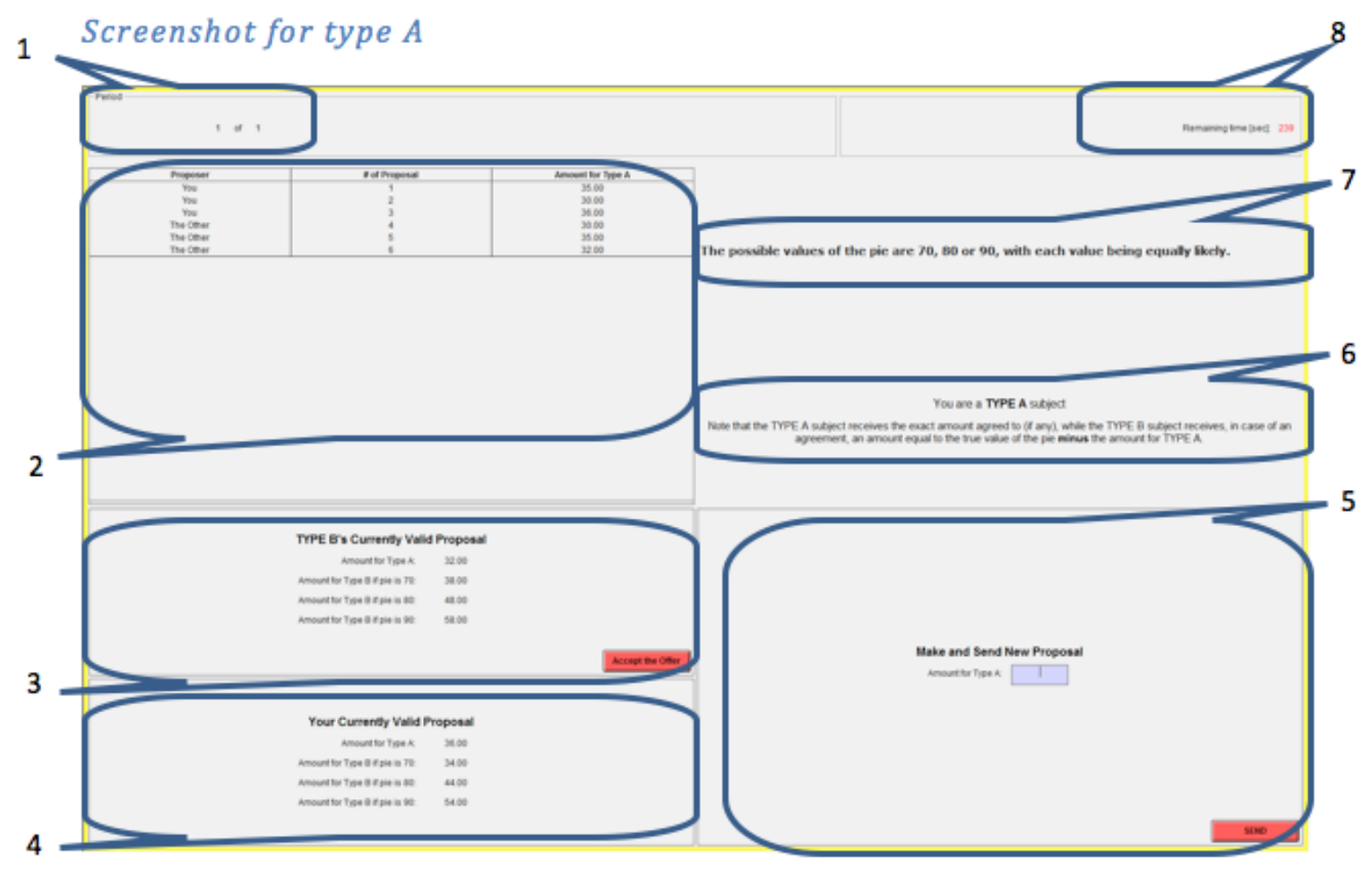

Key

1. Period number box: The number of the current period.

2. Proposal history box: This shows the history of offers you and your match have made.

3. Your match's current offer box: Details of the current offer made by your match. To accept their offer, click on the "Accept the Offer" button.

4. Your current offer box: Details of your current offer.

5. New offer box: To make a new offer enter a value for the fixed payment and click the "SEND" button.

6. Type reminder box: A reminder of your type and how your payoff for the period is calculated should you reach an agreement. 
7. Pie size reminder box: A reminder of the possible sizes of the pie. Each amount is equally likely.

8. Timer box: The amount of time remaining.

Screenshot for type $B$

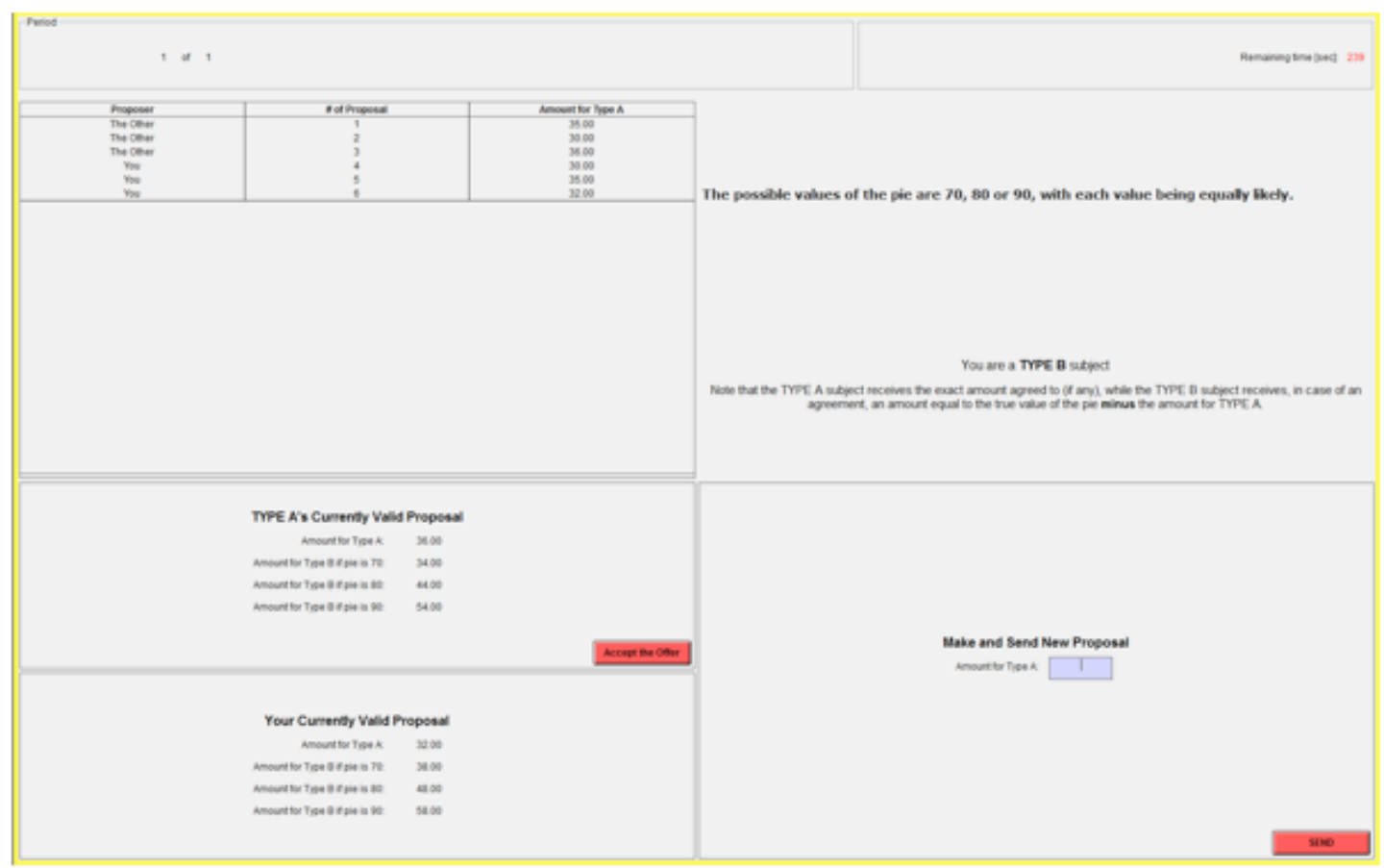




\section{B.2 Endogenous Distribution - Transparent Choice General Instructions}

\section{Welcome}

You are about to participate in a session on interactive decision-making. Thank you for agreeing to take part. The session should last about 90 minutes.

You should have already turned off all mobile phones, smart phones, mp3 players and all such devices by now. If not, please do so immediately. These devices must remain switched off throughout the session. Place them in your bag or on the floor besides you. Do not have them in your pocket or on the table in front of you.

The entire session, including all interaction between you and other participants, will take place through the computer. You are not allowed to talk or to communicate with other participants in any other way during the session. You are asked to follow these rules throughout the session. Should you fail to do so, we will have to exclude you from this (and future) session(s) and you will not receive any compensation for this session. We will start with a brief instruction period. Please read these instructions carefully. They are identical for all participants in this session with whom you will interact. If you have any questions about these instructions or at any other time during the experiment, then please raise your hand. One of the experimenters will come to answer your question.

\section{Structure of the session}

There are two parts to this session. Instructions for the part 1 are detailed below. Part 2 consists of survey and individual choice questions. Instructions for part 2 will be given once part 1 has been completed. Parts 1 and 2 are independent.

\section{Compensation for participation in this session}

You will be able to earn money for your decisions in both parts of this session. What you will earn from part 1 will depend on your decisions, the decisions of others and chance. Further details are given below. What you will earn from part 2 will only depend on your decisions and chance. Further details will be given after part 1 has been completed. In the instructions, and all decision tasks that follow, payoffs are reported in Euros (EUR). Your final payment will be 2 EUR plus the sum of your earnings from the two parts. Final payment takes place in cash at the end of the session. Your decisions and earnings in the session will remain anonymous. 


\section{Instructions for Part I}

\section{Structure of part 1}

Part 1 is structured as follows:

1. At the beginning of part 1, you will be randomly assigned as either a type A or a type B participant. Your type will remain the same for the duration of part 1.

2. Part 1 consists of 10 periods.

3. At the beginning of a period, you will be randomly paired with another participant of a different type. That is, if you were assigned as type A, you will be randomly paired with a participant that was assigned as type B; if you were assigned as type B, you will be randomly paired with a participant assigned as type A.

4. This random pairing procedure is repeated at the beginning of every period.

5. During the period, you will interact only with the participant you have been paired with for that period. We refer to this participant as your match.

\section{Description of periods 1 to 5}

6. During a period you and your match will negotiate over how to divide between you an amount of money. We call the amount of money that you have to divide the pie. However, you will not always know size of the pie for sure. In some periods, there will be only one value that the pie could be (i.e. it is certain), in others there will be two values it could be - with each amount equally likely - and in others there will be three values it could be - again, with each amount equally likely.

7. At the beginning of the period, you and your match will be informed of the list of possible amounts for the pie. This list will vary from period to period. Neither you nor your match will know the actual size of the pie until end of the period. Only at this point will the size of the pie be determined: it will be randomly selected from the list of possible amounts.

8. You will decide on how to divide the pie by negotiating over the value (in Euros) of a fixed payment to the type A participant. These negotiations will take place through the computer interface. You will have 4 minutes in which to negotiate. The time limit is binding: if you and your match do not reach an agreement during this time limit you will both receive zero for the period. 
9. During the negotiation time, you may make offers at any time. An offer is a suggested value for the fixed payment to the type A participant. Note: If you are a type $B$ participant, this will not be your payoff if the offer is accepted.

10. The only restrictions on the offers you can make are: 1) the offer must be larger than zero, and 2) the offer must be less than the smallest possible value for the size of the pie. The computer interface will ensure these restrictions are met. Finally, only the current offer, that is the most recent offer made by a participant, can be accepted by the other participant.

11. An agreement is reached when either you or your match accept the other's current offer. Once an offer has been accepted, negotiations for the period end.

12. If you do agree on a value for the fixed payment, then the payoff in this period for the type A participant will be the agreed payment. The type B participant will receive whatever is left from the pie once the agreed payment has been subtracted. Consequently, if you reach an agreement, type A's payoff will always be certain, whereas type B's payoff will depend on the realised size of the pie.

13. A period is ended either by an agreement or by the elapse of the negotiating time limit.

\section{At the end of a period}

14. At the end of a period, the random pie size, your payoff for the period and that of your match will be determined and displayed.

\section{Description of periods 6 to 10}

15. During periods 6 to 10, you and your match will face a similar situation as in periods 1 to 5 . The only difference is at the beginning of the period, before negotiations begin: the type B participant will be shown two lists of possible amounts for the pie and be asked to choose one of the two lists.

16. As before, neither you nor your match will know the actual size of the pie until the end of the period. Only at this point will the size of the pie be determined: it will be randomly selected from the list of possible amounts.

17. While the type B participant is choosing between the two lists, the type A participant will be informed of the two options the type B participant has. The choice that the type B participant has will vary from period to period.

18. Once the type B participant has made their choice, and before negotiations begin, both participants will be informed of the chosen list of possible amounts for the pie for the current period. 
19. The period then proceeds exactly as before, as described in points 8 to 13 above.

\section{At the end of a period}

20. At the end of a period, the random pie size, your payoff for the period and that of your match will be determined and displayed.

\section{The end of part 1}

21. After a period is finished, you will be randomly paired for a new period. Part 1 consists of 10 such periods.

22. At the end of part 1 - that is, after the tenth period - one period will be selected at random. The payoff you gained during the selected period will be used to as your final payoff for part 1 .

23. After your final payoff for part 1 has been calculated, the session will move on to part 2. Instructions for part 2 will be displayed on your computer terminal. Please read them carefully and proceed through part 2 at your own pace.

\section{Making and Accepting Offers}

\section{An example}

The following screen shot is used as an example to illustrate how you use the computer interface to make and accept offers. The screenshot shows the situation for a type A participant. The layout for a type B participant is analogous. For completeness, the associated screen for the type B participant is shown below.

Please note that the possible sizes of the pie, and the offers shown on the screen, are not values that you will see during the session itself. They have been selected for illustrative purposes only. 


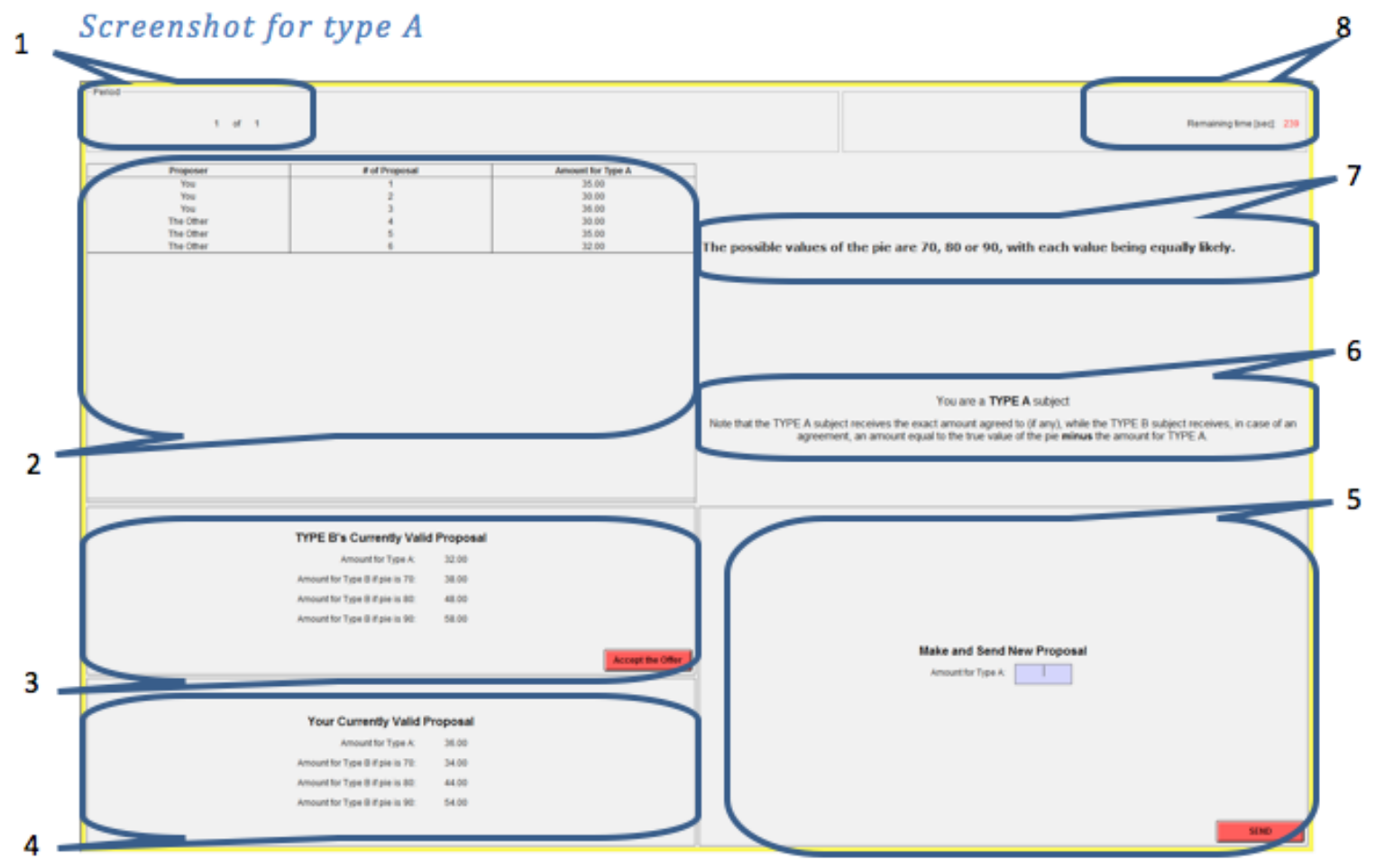

Key

1. Period number box: The number of the current period.

2. Proposal history box: This shows the history of offers you and your match have made.

3. Your match's current offer box: Details of the current offer made by your match. To accept their offer, click on the "Accept the Offer" button.

4. Your current offer box: Details of your current offer.

5. New offer box: To make a new offer enter a value for the fixed payment and click the "SEND" button.

6. Type reminder box: A reminder of your type and how your payoff for the period is calculated should you reach an agreement.

7. Pie size reminder box: A reminder of the possible sizes of the pie. Each amount is equally likely.

8. Timer box: The amount of time remaining. 
Screenshot for type B

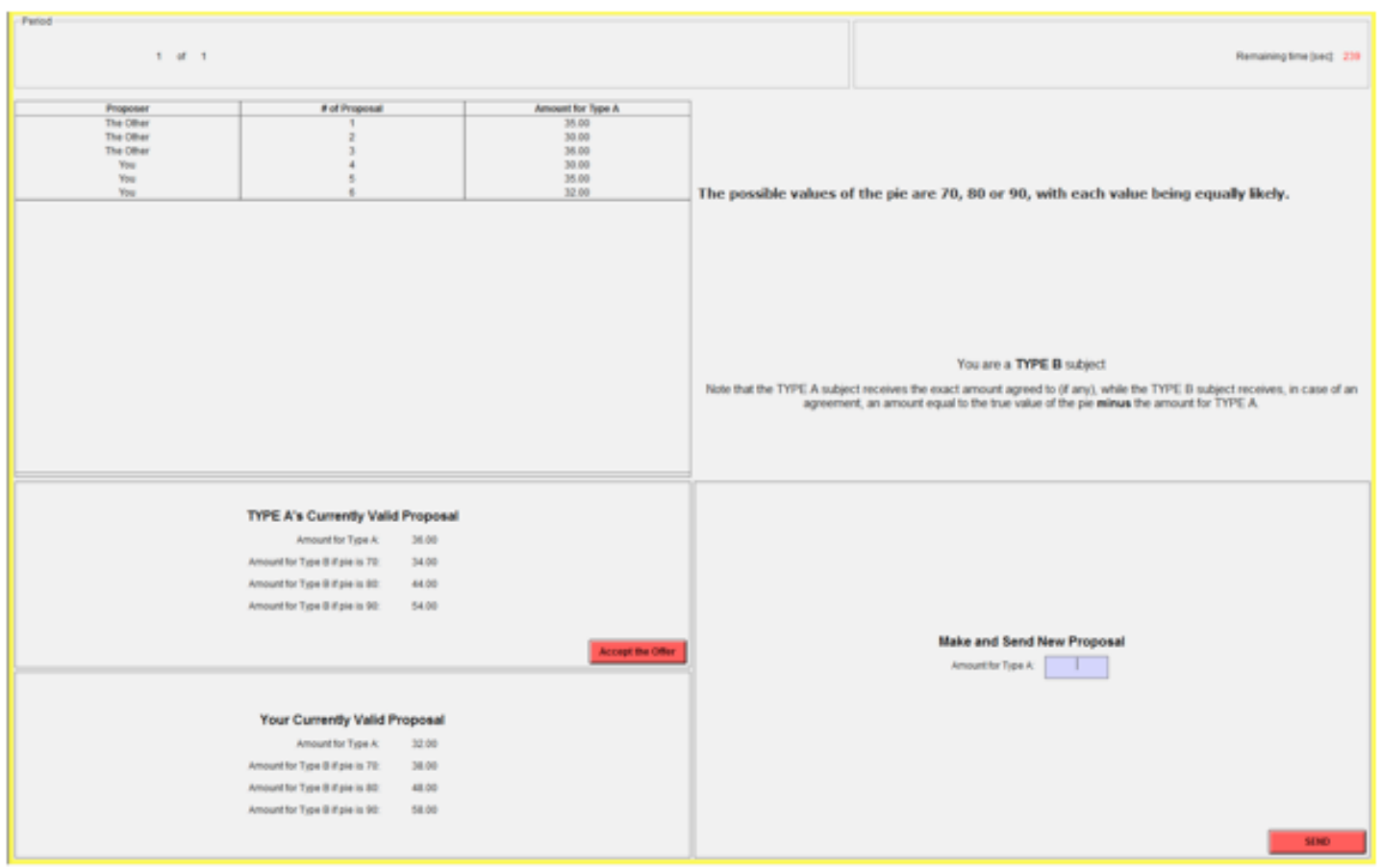




\section{B.3 Endogenous Distribution - Non-Transparent Choice General Instructions}

\section{Welcome}

You are about to participate in a session on interactive decision-making. Thank you for agreeing to take part. The session should last about 90 minutes.

You should have already turned off all mobile phones, smart phones, mp3 players and all such devices by now. If not, please do so immediately. These devices must remain switched off throughout the session. Place them in your bag or on the floor besides you. Do not have them in your pocket or on the table in front of you.

The entire session, including all interaction between you and other participants, will take place through the computer. You are not allowed to talk or to communicate with other participants in any other way during the session. You are asked to follow these rules throughout the session. Should you fail to do so, we will have to exclude you from this (and future) session(s) and you will not receive any compensation for this session. We will start with a brief instruction period. Please read these instructions carefully. They are identical for all participants in this session with whom you will interact. If you have any questions about these instructions or at any other time during the experiment, then please raise your hand. One of the experimenters will come to answer your question.

\section{Structure of the session}

There are two parts to this session. Instructions for the part 1 are detailed below. Part 2 consists of survey and individual choice questions. Instructions for part 2 will be given once part 1 has been completed. Parts 1 and 2 are independent.

\section{Compensation for participation in this session}

You will be able to earn money for your decisions in both parts of this session. What you will earn from part 1 will depend on your decisions, the decisions of others and chance. Further details are given below. What you will earn from part 2 will only depend on your decisions and chance. Further details will be given after part 1 has been completed. In the instructions, and all decision tasks that follow, payoffs are reported in Euros (EUR). Your final payment will be 2 EUR plus the sum of your earnings from the two parts. Final payment takes place in cash at the end of the session. Your decisions and earnings in the session will remain anonymous. 


\section{Instructions for Part I}

\section{Structure of part 1}

Part 1 is structured as follows:

1. At the beginning of part 1, you will be randomly assigned as either a type A or a type B participant. Your type will remain the same for the duration of part 1.

2. Part 1 consists of 10 periods.

3. At the beginning of a period, you will be randomly paired with another participant of a different type. That is, if you were assigned as type A, you will be randomly paired with a participant that was assigned as type B; if you were assigned as type B, you will be randomly paired with a participant assigned as type A.

4. This random pairing procedure is repeated at the beginning of every period.

5. During the period, you will interact only with the participant you have been paired with for that period. We refer to this participant as your match.

\section{Description of periods 1 to 5}

6. During a period you and your match will negotiate over how to divide between you an amount of money. We call the amount of money that you have to divide the pie. However, you will not always know size of the pie for sure. In some periods, there will be only one value that the pie could be (i.e. it is certain), in others there will be two values it could be - with each amount equally likely - and in others there will be three values it could be - again, with each amount equally likely.

7. At the beginning of the period, you and your match will be informed of the list of possible amounts for the pie. This list will vary from period to period. Neither you nor your match will know the actual size of the pie until end of the period. Only at this point will the size of the pie be determined: it will be randomly selected from the list of possible amounts.

8. You will decide on how to divide the pie by negotiating over the value (in Euros) of a fixed payment to the type A participant. These negotiations will take place through the computer interface. You will have 4 minutes in which to negotiate. The time limit is binding: if you and your match do not reach an agreement during this time limit you will both receive zero for the period. 
9. During the negotiation time, you may make offers at any time. An offer is a suggested value for the fixed payment to the type A participant. Note: If you are a type $B$ participant, this will not be your payoff if the offer is accepted.

10. The only restrictions on the offers you can make are: 1) the offer must be larger than zero, and 2) the offer must be less than the smallest possible value for the size of the pie. The computer interface will ensure these restrictions are met. Finally, only the current offer, that is the most recent offer made by a participant, can be accepted by the other participant.

11. An agreement is reached when either you or your match accept the other's current offer. Once an offer has been accepted, negotiations for the period end.

12. If you do agree on a value for the fixed payment, then the payoff in this period for the type A participant will be the agreed payment. The type B participant will receive whatever is left from the pie once the agreed payment has been subtracted. Consequently, if you reach an agreement, type A's payoff will always be certain, whereas type B's payoff will depend on the realised size of the pie.

13. A period is ended either by an agreement or by the elapse of the negotiating time limit.

\section{At the end of a period}

14. At the end of a period, the random pie size, your payoff for the period and that of your match will be determined and displayed.

\section{Description of periods 6 to 10}

15. During periods 6 to 10, you and your match will face a similar situation as in periods 1 to 5 . The only difference is at the beginning of the period, before negotiations begin: the type B participant will be shown two lists of possible amounts for the pie and be asked to choose one of the two lists.

16. This choice will partially determine the list of possible amounts for the pie for the current period: which of the two options is implemented will be randomly determined, but the option chosen by the type B participant will have a greater chance of being chosen.

17. Specifically, the option chosen by the type B participant has a $70 \%$ chance of being implemented, whereas the non-chosen option has a $30 \%$ chance of being implemented. That is, if you were to roll a 10-sided die, the option chosen by the type B participant would be implemented if the numbers 1 through 7 came up, and the other option would be implemented if the numbers 8,9 or 10 came up. 
18. While the type B participant is choosing between the two lists, the type A participant will be informed of the two options the type B participant has. The choice that the type B participant has will vary from period to period.

19. Once the type B participant has made their choice, and before negotiations begin, the computer will randomly determine which of the two options will be implemented - remember, the option chosen by the type B participant has a $70 \%$ chance of being implemented, whereas the option not chosen by the type B participant has a $30 \%$ chance of being implemented.

20. Both participants will then be informed which of the options is implemented for the current period - remember the type A participant will not know whether the type B participant chose this option or not.

21. As before, neither you nor your match will know the actual size of the pie until the end of the period. Only at this point will the size of the pie be determined: it will be randomly selected from the list of possible amounts.

22. The period then proceeds exactly as before, as described in points 8 to 13 above.

\section{At the end of a period}

23. At the end of a period, the random pie size, your payoff for the period and that of your match will be determined and displayed.

\section{The end of part 1}

24. After a period is finished, you will be randomly paired for a new period. Part 1 consists of 10 such periods.

25. At the end of part 1 - that is, after the tenth period - one period will be selected at random. The payoff you gained during the selected period will be used to as your final payoff for part 1 .

26. After your final payoff for part 1 has been calculated, the session will move on to part 2. Instructions for part 2 will be displayed on your computer terminal. Please read them carefully and proceed through part 2 at your own pace.

\section{Making and Accepting Offers}

\section{An example}


The following screen shot is used as an example to illustrate how you use the computer interface to make and accept offers. The screenshot shows the situation for a type A participant. The layout for a type B participant is analogous. For completeness, the associated screen for the type B participant is shown below.

Please note that the possible sizes of the pie, and the offers shown on the screen, are not values that you will see during the session itself. They have been selected for illustrative purposes only.

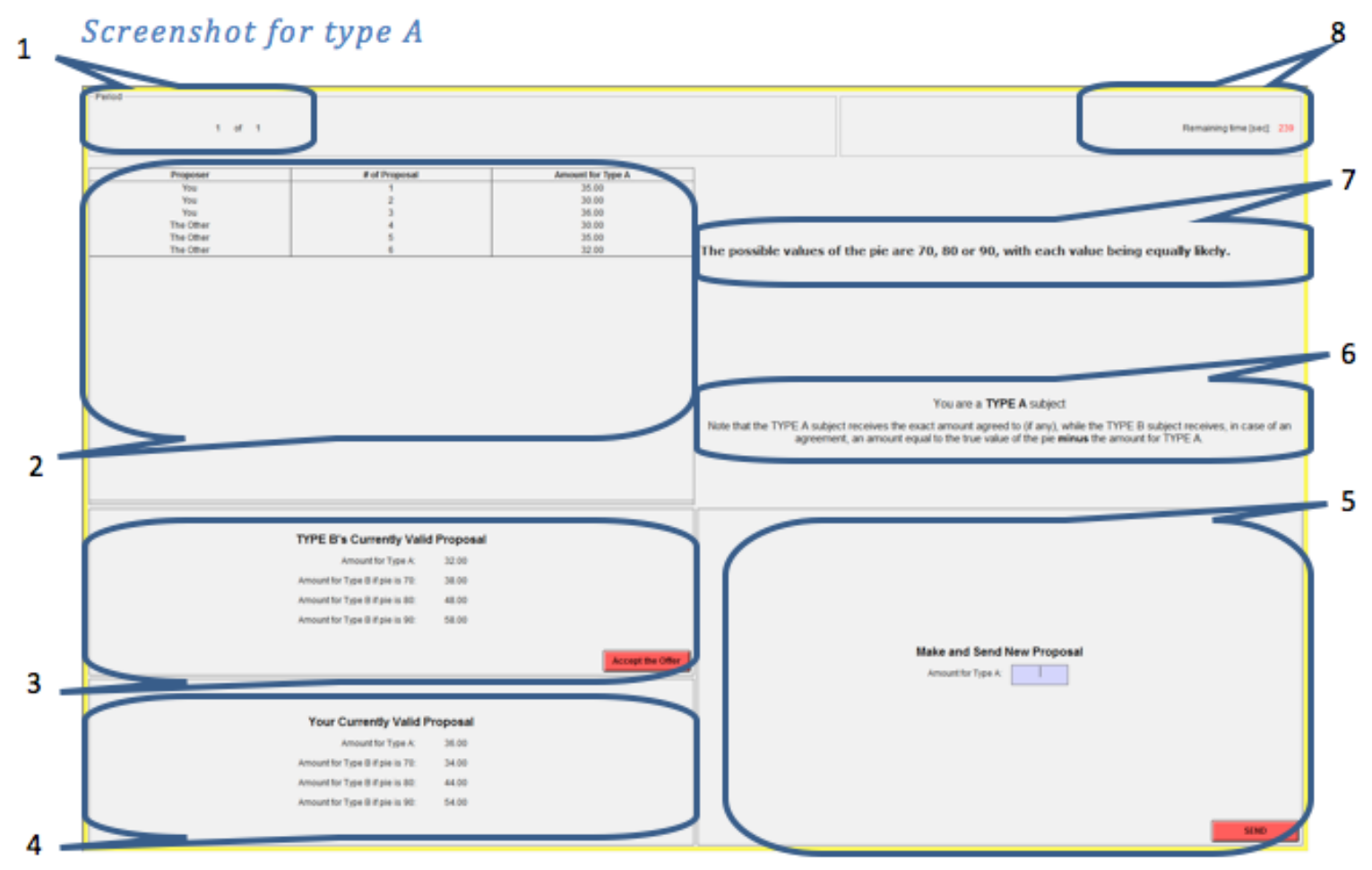

Key

1. Period number box: The number of the current period.

2. Proposal history box: This shows the history of offers you and your match have made.

3. Your match's current offer box: Details of the current offer made by your match. To accept their offer, click on the "Accept the Offer" button.

4. Your current offer box: Details of your current offer.

5. New offer box: To make a new offer enter a value for the fixed payment and click the "SEND" button.

6. Type reminder box: A reminder of your type and how your payoff for the period is calculated should you reach an agreement. 
7. Pie size reminder box: A reminder of the possible sizes of the pie. Each amount is equally likely.

8. Timer box: The amount of time remaining.

Screenshot for type $B$

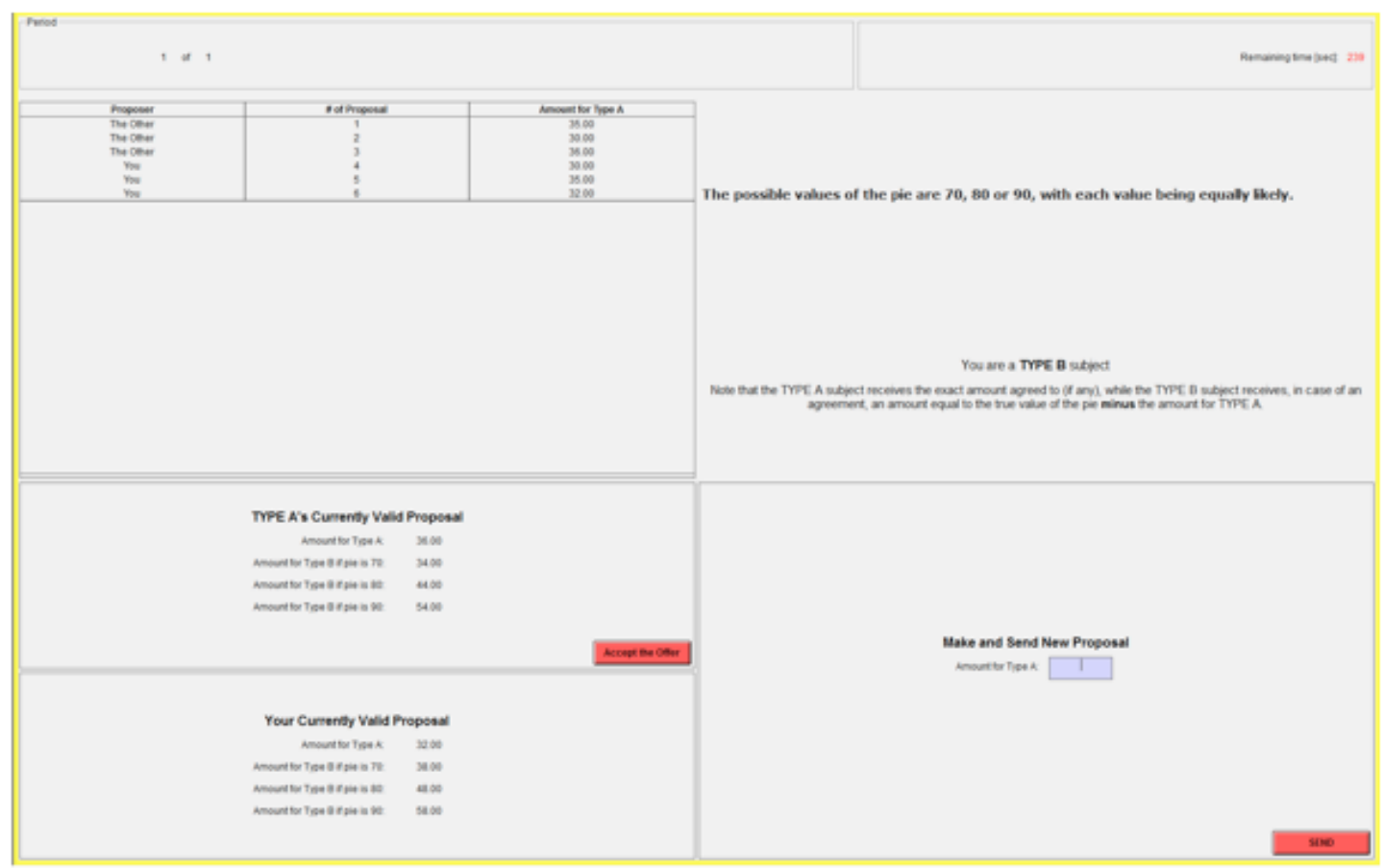




\section{Endogenous Distribution Results: Transparent versus Non- Transparent Choice}

Table C.1 shows the proportion of RC players choosing the riskier distribution separately for the transparent-choice and non-transparent-choice conditions. Overall, transparency does not appear to be a salient concern. In particular, it is not the case that RC players under the non-transparent condition consistently choose the riskier distribution more often.

Table C.1: Percent of RCs Choosing Riskier Distribution by Transparency Condition (Periods 6-10) Including the TC versus NTC Contrast

\begin{tabular}{|c|c|c|c|c|c|c|}
\hline \multirow[b]{2}{*}{ Alternatives } & \multicolumn{3}{|c|}{ Transparent Choice } & \multicolumn{3}{|c|}{ Non-Transparent Choice } \\
\hline & Low Risk & High Risk & Combined & Low Risk & High Risk & Combined \\
\hline Certain versus Tertiary & 58.3 & 41.7 & 50.0 & 45.8 & 62.5 & 54.2 \\
\hline Certain versus Binary & 29.2 & 33.3 & 31.2 & 33.3 & 45.8 & 39.6 \\
\hline Tertiary versus Binary & 37.5 & 20.8 & 29.2 & 25.0 & 29.2 & 27.1 \\
\hline$(16,20,24)$ versus $(12,20,28)$ & 25.0 & 29.2 & 27.1 & 29.2 & 20.8 & 25.0 \\
\hline$(16,24)$ versus $(12,28)$ & 37.5 & 8.3 & 22.9 & 37.5 & 16.7 & 27.1 \\
\hline
\end{tabular}

This fact can be seen most easily by comparing specifications (1) and (2) of Table C.2, which runs a linear random-effect regression on a complete set of alternative dummies (the certain versus tertiary alternative is the baseline of these regressions) separately for the transparent and non-transparent conditions. For either condition the main observations with respect to distribution choice from Section 3.3 hold: there is a general reluctance to choose the riskier of the two distributions with the certain versus tertiary alternative being the notable exception, where around $50 \%$ of RCs choose the tertiary alternative. The only effect of non-transparency appears to be a marginally significant increase in the proportion of RCs choosing the binary distributions over the certain distribution; there is no direct effect or interaction-with- $\rho_{R C}$ effect - see specification (3).

Tables C.3 and C.4 investigate the bargaining outcomes after the distribution choice has been made. Again there is no overall consistent effect from making the distribution choice non-transparent. For agreed FP payments - Table C.3 - the effect of risk and the role of the FP player's attitude towards risk show up more strongly in the non-transparent setting than the transparent one. However, the opposite is true for the role of the RC player's attitude towards risk.

For disagreements - Table C.4 - there is a significant increase for both tertiary distributions in the non-transparent setting; something that is not seen in the transparent setting and runs counter to the behavioural prediction that the non-transparent setting should mask intentions. However, much of the significant increases in disagreement rates in the non-transparent setting disappear once a dummy variable for whether the riskier of the two distributions was implemented is included, leaving just a large increase for the $(16,20,24)$. 
Table C.2: Linear Random-Effects Regression of Choice of Distribution (Periods 6-10) Including the TC versus NTC Contrast

\begin{tabular}{|c|c|c|c|}
\hline & \multicolumn{3}{|c|}{ Riskier Distribution Chosen } \\
\hline & $(1)$ & $(2)$ & $(3)$ \\
\hline $\mathbf{1}[$ Certain versus Binary] & $-0.25^{* *}(0.105)$ & $-0.07 \quad(0.082)$ & \\
\hline $\mathbf{1}[$ Tertiary versus Binary] & $-0.20^{* *}(0.094)$ & $-0.24^{* * *}(0.089)$ & \\
\hline $\mathbf{1}[(16,20,24)$ versus $(12,20,28)]$ & $-0.23^{* * *}(0.086)$ & $-0.29^{* * *}(0.081)$ & \\
\hline $\mathbf{1}[(16,24)$ versus $(12,28)]$ & $-0.28^{* * *}(0.095)$ & $-0.27^{* * *}(0.085)$ & \\
\hline $\mathbf{1}[$ Certain versus Tertiary] & & & $0.25^{* * *}(0.049)$ \\
\hline $\mathbf{1}[$ Certain verus Binary] $\times \mathbf{1}[$ Non-Transparent] & & & $0.19^{*} \quad(0.105)$ \\
\hline $\mathbf{1}[$ Non-Transparent] & & & $-0.06 \quad(0.076)$ \\
\hline$\rho_{R C}$ & & & $-0.29^{* * *}(0.078)$ \\
\hline$\rho_{R C} \times \mathbf{1}[$ Non-Transparent $]$ & & & $0.13 \quad(0.161)$ \\
\hline Constant & $0.51^{* * *}(0.055)$ & $0.49^{* * *}(0.065)$ & $0.34^{* * *}(0.049)$ \\
\hline $\mathrm{R}^{2}$ & 0.04 & 0.06 & 0.08 \\
\hline Observations & 206 & 206 & 412 \\
\hline Transparency Condition & $\mathrm{TC}$ & NTC & - \\
\hline
\end{tabular}

Notes: Data includes only observations for which $\left|\rho_{i}\right|<1$ for both RC and FP players. ${ }^{* * *} 1 \%,{ }^{* *} 5 \%,{ }^{*} 10 \%$ significance using standard errors clustered at the matching group level.

Table C.3: Linear Random-Effects Regressions of Agreed FP Payments in the Endogenous Environment (Periods 6-10) Including the TC versus NTC Contrast

\begin{tabular}{|c|c|c|c|c|c|}
\hline \multirow[b]{3}{*}{ Variance } & \multirow{2}{*}{\multicolumn{2}{|c|}{ (1) }} & \multicolumn{2}{|c|}{ Agreed FP Payments } & \multirow[b]{2}{*}{ (4) } \\
\hline & & & $(2)$ & $(3)$ & \\
\hline & -1.03 & $(0.677)$ & $-1.90^{* * *}(0.593)$ & $-0.66 \quad(0.676)$ & $-2.22^{* *} \quad(0.958)$ \\
\hline 1[Riskier Dist.] & 0.02 & $(0.364)$ & $0.23 \quad(0.414)$ & $-0.05 \quad(0.351)$ & $0.28 \quad(0.403)$ \\
\hline$\rho_{F P}$ & & & & $-0.47 \quad(1.033)$ & $-2.15^{* * *}(0.638)$ \\
\hline$\rho_{R C}$ & & & & $0.54^{*} \quad(0.297)$ & $-0.48 \quad(0.957)$ \\
\hline$\rho_{R C} \times$ Var. & & & & $-2.22^{* * *}(0.633)$ & $(1.599)$ \\
\hline $\mathrm{R}^{2}$ & 0.04 & & 0.10 & 0.06 & 0.20 \\
\hline Observations & 189 & & 182 & 189 & 182 \\
\hline Transparency Condition & $\mathrm{TC}$ & & NTC & $\mathrm{TC}$ & NTC \\
\hline
\end{tabular}

Notes: Data includes only observations for which $\left|\rho_{i}\right|<1$ for both RC and FP players. ${ }^{* * *} 1 \%,{ }^{* *} 5 \%$, ${ }^{*} 10 \%$ significance using standard errors clustered at the matching group level.

\section{Endogenous Distribution Results: First Five Periods}

Table D.1 presents summary statistics, and Table D.2 complete pairwise comparisons across distributions, of the bargaining outcomes and fairness perceptions for the first five periods, when the distribution was exogenously specified. As can be seen these results reflect those for the exogenous-distribution sessions presented in Section 2.3. In particular, agreed payments to FP players are significantly lower with risk, confirming Hypothesis 1. Furthermore, Hypothesis 4 is rejected: as the risk increases, the frequency of disagreements increases and significantly so for the two low-risk distributions.

Table D.3 replicates the analysis of Table 2. With respect to Hypothesis 2, for a given 
Table C.4: Linear Random-Effects Regressions of Disagreements in the Endogenous Environment (Periods 6-10) Including the TC versus NTC Contrast

\begin{tabular}{|c|c|c|c|c|c|c|c|c|}
\hline \multirow[b]{3}{*}{$\mathbf{1}[(16,20,24)]$} & \multicolumn{8}{|c|}{ Disagreements } \\
\hline & \multicolumn{2}{|c|}{ (1) } & \multicolumn{2}{|c|}{ (2) } & \multicolumn{2}{|c|}{$(3)$} & \multicolumn{2}{|c|}{$(4)$} \\
\hline & 0.07 & $(0.060)$ & $0.19^{* *}$ & $(0.074)$ & 0.05 & $(0.061)$ & $0.17^{* *}$ & $(0.078)$ \\
\hline $\mathbf{1}[(16,24)]$ & 0.06 & $(0.055)$ & $0.09^{* *}$ & $(0.037)$ & 0.04 & $(0.051)$ & 0.06 & $(0.042)$ \\
\hline $\mathbf{1}[(12,20,28)]$ & $-0.04^{*}$ & $(0.025)$ & $0.13^{* * *}$ & $(0.048)$ & $-0.08^{*}$ & $(0.045)$ & 0.07 & $(0.046)$ \\
\hline $\mathbf{1}[(12,28)]$ & $0.17^{* * *}$ & $(0.065)$ & 0.07 & $(0.068)$ & 0.10 & $(0.094)$ & -0.00 & $(0.089)$ \\
\hline $\mathbf{1}$ [Riskier Dist.] & & & & & 0.07 & $(0.062)$ & $0.08^{*}$ & $(0.041)$ \\
\hline Constant & $0.04^{*}$ & $(0.025)$ & 0.02 & $(0.024)$ & $0.04^{*}$ & $(0.025)$ & 0.02 & $(0.024)$ \\
\hline $\mathrm{R}^{2}$ & 0.05 & & 0.04 & & 0.06 & & 0.05 & \\
\hline Observations & 206 & & 206 & & 206 & & 206 & \\
\hline Transparency Condition & $\mathrm{TC}$ & & NTC & & $\mathrm{TC}$ & & NTC & \\
\hline
\end{tabular}

Notes: Data includes only observations for which $\left|\rho_{i}\right|<1$ for both RC and FP players. ${ }^{* * *} 1 \%,{ }^{* *} 5 \%,{ }^{*} 10 \%$ significance using standard errors clustered at the matching group level.

Table D.1: Bargaining Outcomes and Fairness Perceptions in the Endogenous Environment (Periods 1-5)

\begin{tabular}{|c|c|c|c|c|c|c|}
\hline \multirow{2}{*}{$\begin{array}{c}\text { Distribution } \\
\text { of Pie }\end{array}$} & \multirow{2}{*}{$\begin{array}{c}\text { Final FP } \\
\text { Earnings }(€)\end{array}$} & \multirow{2}{*}{$\begin{array}{c}\text { Agreed FP } \\
\text { Payments }(€)\end{array}$} & \multirow{2}{*}{$\begin{array}{c}\text { Disagreements } \\
(\%)\end{array}$} & \multirow{2}{*}{$\begin{array}{l}\text { Remaining } \\
\text { Time (sec) }\end{array}$} & \multicolumn{2}{|c|}{ Fair Payment to FP } \\
\hline & & & & & $\mathrm{FP}(€)$ & $\mathrm{RC}(€)$ \\
\hline$(20)$ & 10.17 & 10.62 & 4.2 & 135 & 10.02 & 10.10 \\
\hline$(16,20,24)$ & 8.73 & 9.79 & 10.4 & 72 & 10.45 & 9.78 \\
\hline$(16,24)$ & 8.69 & 9.88 & 11.5 & 95 & 10.19 & 9.20 \\
\hline$(12,20,28)$ & 8.47 & 9.13 & 7.3 & 58 & 9.85 & 8.66 \\
\hline$(12,28)$ & 8.20 & 8.99 & 8.3 & 66 & 9.58 & 8.56 \\
\hline
\end{tabular}

Table D.2: Pairwise Comparison of Bargaining Outcomes in the Endogenous Environment (Periods 1-5)

\begin{tabular}{|c|c|c|c|c|c|c|c|c|c|c|}
\hline & $(20)$ & $(16,20,24)$ & $(16,24)$ & $(12,20,28)$ & $(12,28)$ & $(20)$ & $(16,20,24)$ & $(16,24)$ & $(12,20,28)$ & $(12,28)$ \\
\hline & \multicolumn{5}{|c|}{ Final Earnings } & \multicolumn{5}{|c|}{ Agreed FP Payments } \\
\hline$(20)$ & 10.17 & $>^{* * *}$ & $>^{* * *}$ & $>^{* * *}$ & $>^{* * *}$ & 10.62 & $>^{* *}$ & $>^{* * *}$ & $>^{* * *}$ & $>^{* * *}$ \\
\hline$(16,20,24)$ & & 8.73 & $>$ & $>$ & $>$ & & 9.79 & $<$ & $>^{* * *}$ & $>^{* * *}$ \\
\hline$(16,24)$ & & & 8.69 & $>$ & $>$ & & & 9.88 & $>^{* * *}$ & $>^{* * *}$ \\
\hline$(12,20,28)$ & & & & 8.47 & $>$ & & & & 9.13 & $>$ \\
\hline \multirow[t]{2}{*}{$(12,28)$} & & & & & 8.20 & & & & & 8.99 \\
\hline & \multicolumn{5}{|c|}{ Disagreements } & \multicolumn{5}{|c|}{ Time Remaining } \\
\hline$(20)$ & 4.2 & $<^{* *}$ & $<^{* *}$ & $<$ & $<$ & 135 & $>^{* * *}$ & $>^{* * *}$ & $>^{* * *}$ & $>^{* * *}$ \\
\hline$(16,20,24)$ & & 10.4 & $<$ & $>$ & $>$ & & 72 & $<^{* *}$ & $>$ & $>$ \\
\hline$(16,24)$ & & & 11.5 & $>$ & $>$ & & & 95 & $>^{* * *}$ & $>^{* *}$ \\
\hline$(12,20,28)$ & & & & 7.3 & $<$ & & & & 58 & $<$ \\
\hline$(12,28)$ & & & & & 8.3 & & & & & 66 \\
\hline
\end{tabular}

Notes: The symbol indicates how the outcome measure of the row distribution compares (statistically) to the column distribution. ${ }^{* *} 1 \%,{ }^{* *} 5 \%,{ }^{*} 10 \%$ significance using standard errors clustered at the matching group level. 
distribution, agreed payments to FP players are decreasing in the FP's own risk aversion, consistent with the results from the exogenous-distribution session. The coefficients for the $\mathrm{RC}$ player's risk aversion and its interaction with risk, however, are insignificant and of the wrong sign, although by the second half of the experiment these terms have the expected sign, even if the overall effect is still negative - see Table 7 of the main text. With respect to Hypothesis 3, consistent with the exogenous-distribution sessions, it is the relatively less risk averse RC players that benefit from risk - see Table 8 of the main text.

Table D.3: Linear Random-Effects Regression of Agreed Payments to the FP Player in the Endogenous Environment (Periods 1-5)

\begin{tabular}{|c|c|c|c|c|}
\hline & \multicolumn{4}{|c|}{ Agreed FP Payments } \\
\hline & (1) & $(2)$ & $(3)$ & $(4)$ \\
\hline $\mathbf{1}[(16,20,24)]$ & $-1.10^{* * *}(0.335)$ & & & \\
\hline $\mathbf{1}[(16,24)]$ & $-0.85^{* * *}(0.285)$ & & & \\
\hline $\mathbf{1}[(12,20,28)]$ & $-1.60^{* * *}(0.322)$ & & & \\
\hline $\mathbf{1}[(12,28)]$ & $-1.64^{* * *}(0.347)$ & & & \\
\hline Variance & & $-1.42^{* * *}(0.299)$ & $-1.43^{* * *}(0.298)$ & $-1.63^{* * *}(0.488)$ \\
\hline$\rho_{F P}$ & & & $-1.12^{* *}(0.520)$ & $-1.14^{* *} \quad(0.538)$ \\
\hline$\rho_{R C}$ & & & $-0.95^{* *} \quad(0.379)$ & $-1.24 \quad(0.811)$ \\
\hline$\rho_{R C} \times$ Var & & & & $0.64 \quad(1.067)$ \\
\hline Constant & $10.78^{* * *}(0.301)$ & $10.34^{* * *}(0.217)$ & $11.05^{* * *}(0.323)$ & $11.14^{* * *}(0.424)$ \\
\hline $\mathrm{R}^{2}$ & 0.09 & 0.06 & 0.10 & 0.11 \\
\hline Observations & 378 & 378 & 378 & 378 \\
\hline
\end{tabular}

Notes: Data includes only observations for which $\left|\rho_{i}\right|<1$ for both RC and FP players. ${ }^{* * *} 1 \%,{ }^{* *} 5 \%,{ }^{*} 10 \%$ significance using standard errors clustered at the matching group level. 